\title{
NOGAPS-ALPHA model simulations of stratospheric ozone during the SOLVE2 campaign
}

\author{
J. P. McCormack ${ }^{1}$, S. D. Eckermann ${ }^{1}$, L. Coy ${ }^{1}$, D. R. Allen ${ }^{2}$, Y.-J. Kim ${ }^{3}$, T. Hogan ${ }^{3}$, B. Lawrence ${ }^{4}$, A. Stephens ${ }^{4}$, \\ E. V. Browell ${ }^{5}$, J. Burris ${ }^{6}$, T. McGee $^{6}$, and C. R. Trepte ${ }^{5}$ \\ ${ }^{1}$ E.O. Hulburt Center for Space Research, Naval Research Laboratory, Washington DC, USA \\ ${ }^{2}$ Remote Sensing Division, Naval Research Laboratory, Washington DC, USA \\ ${ }^{3}$ Marine Meteorology Division, Naval Research Laboratory, Monterey, California, USA \\ ${ }^{4}$ British Atmospheric Data Center, Rutherford Appleton Laboratory, Oxfordshire, UK \\ ${ }^{5}$ NASA Langley Research Center, Hampton, Virginia, USA \\ ${ }^{6}$ NASA Goddard Space Flight Center, Greenbelt, Maryland, USA
}

Received: 17 June 2004 - Published in Atmos. Chem. Phys. Discuss.: 4 August 2004

Revised: 20 October 2004 - Accepted: 19 November 2004 - Published: 2 December 2004

\begin{abstract}
This paper presents three-dimensional prognostic $\mathrm{O}_{3}$ simulations with parameterized gas-phase photochemistry from the new NOGAPS-ALPHA middle atmosphere forecast model. We compare 5-day NOGAPS-ALPHA hindcasts of stratospheric $\mathrm{O}_{3}$ with satellite and DC-8 aircraft measurements for two cases during the SOLVE II campaign: (1) the cold, isolated vortex during 11-16 January 2003; and (2) the rapidly developing stratospheric warming of 1722 January 2003. In the first case we test three different photochemistry parameterizations. NOGAPS-ALPHA $\mathrm{O}_{3}$ simulations using the NRL-CHEM2D parameterization give the best agreement with SAGE III and POAM III profile measurements. 5-day NOGAPS-ALPHA hindcasts of polar $\mathrm{O}_{3}$ initialized with the NASA GEOS4 analyses produce better agreement with observations than do the operational ECMWF $\mathrm{O}_{3}$ forecasts of case 1. For case 2, both NOGAPS-ALPHA and ECMWF 114-h forecasts of the split vortex structure in lower stratospheric $\mathrm{O}_{3}$ on 21 January 2003 show comparable skill. Updated ECMWF $\mathrm{O}_{3}$ forecasts of this event at hour 42 display marked improvement from the 114-h forecast; corresponding updated 42-hour NOGAPSALPHA prognostic $\mathrm{O}_{3}$ fields initialized with the GEOS4 analyses do not improve significantly. When NOGAPSALPHA prognostic $\mathrm{O}_{3}$ is initialized with the higher resolution ECMWF $\mathrm{O}_{3}$ analyses, the NOGAPS-ALPHA 42-hour lower stratospheric $\mathrm{O}_{3}$ fields closely match the operational 42-hour ECMWF $\mathrm{O}_{3}$ forecast of the 21 January event. We find that stratospheric $\mathrm{O}_{3}$ forecasts at high latitudes in winter can depend on both model initial conditions and the treatment of photochemistry over periods of 1-5 days. Over-
\end{abstract}

Correspondence to: J. P. McCormack

(mccormack@nrl.navy.mil) all, these results show that the new $\mathrm{O}_{3}$ initialization, photochemistry parameterization, and spectral transport in the NOGAPS-ALPHA NWP model can provide reliable shortrange stratospheric $\mathrm{O}_{3}$ forecasts during Arctic winter.

\section{Introduction}

The Navy Operational Global Atmospheric Prediction System (NOGAPS) is the U.S. Department of Defense's (DoD's) high-resolution global numerical weather prediction (NWP) system, run operationally at the Navy's Fleet Numerical Meteorology and Oceanography Center (FNMOC). NOGAPS is a complete NWP system that includes data quality control (Baker, 1992), tropical cyclone bogusing (Goerss and Jeffries, 1994), operational data assimilation (Goerss and Phoebus, 1992; Daley and Barker, 2001), nonlinear normal mode initialization (Errico et al., 1988), and a global spectral forecast model (Hogan and Rosmond, 1991; Hogan et al., 1991). NOGAPS forecasts are distributed to numerous defense and civilian users for input to environmental prediction systems such as FNMOC's ocean wave, sea ice, ocean thermodynamics, and tropical cyclone models.

NOGAPS forecasts also support various aircraft and shiprouting programs, a capability that was utilized during NASA's second SAGE III Ozone Loss and Validation Experiment (SOLVE2), from January-February 2003. The first two authors used NOGAPS forecasts in the field as part of the Naval Research Laboratory's (NRL) in-field flight-planning support for NASA's instrumented DC-8 research aircraft. Specific applications included forecasting anticyclonic "minihole" systems whose synoptic uplift

(C) 2004 Author(s). This work is licensed under a Creative Commons License. 
and adiabatic cooling might form polar stratospheric clouds (PSCs) (McCormack and Hood, 1997), and initialization of other NRL models that predicted in-flight mountain wave turbulence for the DC- 8 and areas of possible mountain wave PSC formation (Eckermann et al., 2004a). These forecasts played important roles in devising scientifically valuable DC8 flights during SOLVE2, such as the 4 February 2003 flight that measured mountain wave PSCs within an evolving minihole event over Iceland.

Despite these stratospheric applications during SOLVE2, operational NOGAPS forecasts currently focus primarily on the troposphere. As part of a major initiative to improve its NWP and data assimilation capabilities, a new prototype version of the NOGAPS global-spectral circulation model (GCM) has been developed over the past several years (Eckermann et al., 2004b) which extends the model through the stratosphere and into the mesosphere. This new Advanced Level Physics-High Altitude (ALPHA) version of the NOGAPS GCM is described in Sect. 2.

One major focus of development in NOGAPS-ALPHA has been to add ozone to the GCM as a fully interactive threedimensional prognostic variable. The addition of prognostic ozone is a necessary first step toward the goal of assimilating and forecasting ozone fields using NOGAPS. This development supports concurrent efforts to operationally assimilate satellite radiances directly using NRL's new Atmospheric Variational Data Assimilation System (NAVDAS) (Daley and Barker, 2001; Goerss et al., 2003), potentially improving overall NWP performance in several ways. For example, prognostic ozone can help correct complex biases in some longwave radiance channels due to ozone absorption (Derber and Wu, 1998). Prognostic ozone fields, when fed into the radiation calculations, should also improve stratospheric heating/cooling rates and surface radiation fluxes. Operational assimilation of satellite ozone data into NOGAPS may also add valuable meteorological information that can aid overall forecast skill (Jang et al., 2003). These types of issues have motivated ozone assimilation and forecasting efforts at other operational centers, such as the National Centers for Environmental Prediction (NCEP), the European Center for Medium Range Weather Forecasts (ECMWF), and NASA's Global Modeling and Assimilation Office (GMAO).

The combination of ozone and ozone-related observations from a variety of satellite and airborne instruments makes the SOLVE2 winter an ideal period for running NOGAPSALPHA in hindcast mode to test the performance of our new initialization, advection and photochemistry algorithms for ozone. This is the primary focus of the present work. In addition to conducting comparisons with satellite and aircraft ozone measurements, we also compare our NOGAPSALPHA ozone fields with ozone forecasts and analyses issued operationally by the ECMWF and with the NASA GEOS4 ozone analyses.

It is particularly interesting to assess the performance of current NWP ozone analysis/forecast methods within the context of the SOLVE2 mission. For NWP systems, costbenefit considerations do not currently justify the use of the detailed multi-reaction chemistry and photolysis schemes for ozone currently used in some state-of-the-art climatechemistry models and offline chemical transport models. Thus, in common with other NWP models like the ECMWF Integrated Forecast System (IFS) and the NCEP Global Forecasting System (GFS), NOGAPS-ALPHA uses much simpler (and faster) linearized ozone photochemistry schemes that efficiently parameterize the major homogeneous photochemical dependences. The accuracy of these parameterizations in real meteorological situations is not clear, and ozone forecasts issued by NWP models using these schemes have not been subjected to detailed comparisons with data to answer these questions experimentally.

The SOLVE2 case studies in this paper provide initial validation assessments of NOGAPS-ALPHA prognostic ozone using parameterized photochemistry schemes. These assessments will guide future NWP model development. For example, the potential for heterogeneous ozone loss in the Arctic is highly sensitive to the synoptic meteorological conditions. This process only becomes important if the vortex is stable and thus cold. Within the linearized ozone photochemistry framework, heterogeneous reactions producing catalytic ozone losses can be parameterized using, e.g. an additional chlorine loading term (Dethof, 2003), or a so-called coldtracer scheme (Braesicke et al., 2003). Whether or not such developments are justified depends on the impact of the omitted effects on NWP skill relative to the requisite computational overhead. Both the basic linearized gas phase ozone photochemistry parameterizations and the NWP model's internal transport algorithms must be able to capture observed features in the polar ozone distribution (e.g. ozone lamination due to vortex filaments) before additional heterogeneous terms can then potentially yield an improved ozone forecast. This paper presents first-order assessments of these parameterizations based on model-data comparisons for select cases during the SOLVE II campaign.

The meteorological conditions during the SOLVE2 winter period allow us to study the performance of NOGAPSALPHA prognostic ozone fields under both relatively quiescent and disturbed polar vortex conditions. From early December 2002 to mid-January 2003, the Arctic polar vortex was relatively stable and lower stratospheric temperatures were cold enough to form PSCs. A stratospheric warming beginning on or around 17 January 2003 caused the vortex to split into two distinct lobes by 21 January (Urban et al., 2004). Figure 1 depicts the rapid change in $30 \mathrm{hPa}$ minimum temperatures over the Northern polar region during January 2003.

This paper presents results from NOGAPS-ALPHA hindcast runs (with prognostic ozone activated) that span these two distinctly different periods in January 2003. Case 1 (see Fig. 1) corresponds nominally to the DC-8 flight of 14 January 2000 , during the period of cold, relatively undisturbed 


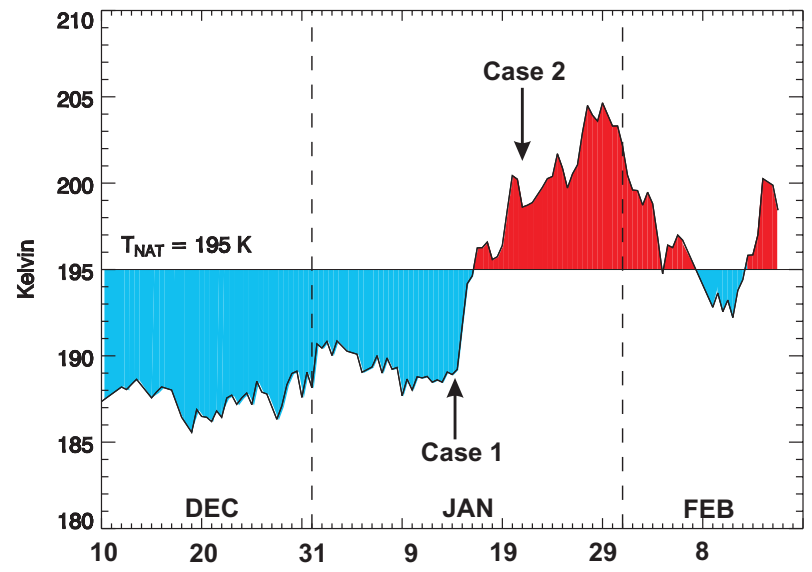

Fig. 1. Time series of minimum $30 \mathrm{hPa}$ temperatures within $60^{\circ}-$ $90^{\circ} \mathrm{N}$ during the period 10 December 2002-18 February 2003 taken from operational NOGAPS MVOI analyses. Dotted vertical lines separate individual months. DC-8 flights on 14 January and 21 January are indicated as Case 1 and Case 2, respectively. Horizontal line denotes nominal $195 \mathrm{~K}$ PSC formation temperature threshold at $30 \mathrm{hPa}$.

vortex conditions that existed during 11-16 January. Our NOGAPS-ALPHA forecasts are initialized on 11 January and run throughout this 5-day period. Our comparisons here focus on the full ozone profile throughout the stratosphere, and thus we compare mostly with satellite data since DC-8 ozone profiles do not extend quite as high. Case 2 focuses on the DC-8 flight on 21 January, toward the end period of the rapid initial warming of the stratosphere and splitting of the vortex during 17-22 January. The complex meteorology of this event is used as a rigorous test of NOGAPS-ALPHA model dynamics and transport. For this case, we compare more closely with DC-8 lidar data along a flight track at heights $\sim 13-30 \mathrm{~km}$. At the altitudes and latitudes of the SOLVE2 DC-8 flights, the ozone photochemical relaxation times are fairly long, and so model initialization and transport effects should dominate. These case studies are the first assessments of NOGAPS-ALPHA model performance.

The paper is organized as follows: Sect. 2 provides a description of the major modifications of the NOGAPSALPHA GCM compared to the current operational NOGAPS; Sect. 3 gives an overview of the various data sources used to validate the NOGAPS-ALPHA simulations; Sect. 4 focuses on the period of 11-16 January 2003, presenting an intercomparison of 3 different ozone photochemistry schemes in NOGAPS-ALPHA validated with a combination of SAGE III and POAM III ozone profile measurements; Sect. 5 presents an assessment of NOGAPS-ALPHA prognostic ozone during the rapidly developing stratospheric warming period 17-22 January 2003; Sect. 6 summarizes these results and outlines future research directions.

\section{Model description}

This section presents a brief overview of the new NOGAPSALPHA NWP model. Additional details can be found in Eckermann et al. (2004b)

\subsection{Overview of NOGAPS GCM and Operational Schemes}

The NOGAPS GCM is an Eulerian spectral model currently run operationally with triangular truncation at zonal and meridional wavenumber 239 (T239), roughly equivalent to $0.5^{\circ}$ latitude-longitude spacing. It utilizes a generalized vertical coordinate within an energy conserving vertical finite difference formulation (Kasahara, 1974; Simmons and Burridge, 1981; Hogan and Rosmond, 1991). The model's dynamical variables are relative vorticity, divergence, virtual potential temperature, specific humidity, and terrain (surface) pressure. The model is central in time with a semi-implicit treatment of gravity wave propagation and Robert (Asselin) time filtering (Simmons et al., 1978).

The current operational model's physics packages include a bulk Richardson number-dependent vertical mixing scheme (Louis et al., 1982), a time-implicit Louis surface flux parameterization (Louis, 1979), orographic gravity wave and flow-blocking drag (Webster et al., 2003), shallow cumulus mixing of moisture, temperature, and winds (Tiedtke, 1984), the Emanuel cumulus parameterization (Emanuel and Zivkovic-Rothman, 1999; Peng et al., 2004), convective, stratiform and boundary-layer cloud parameterizations (Slingo, 1987; Teixeira and Hogan, 2002), and a shortwave and longwave radiation scheme (Harshvardhan et al., 1987).

These operational schemes are available for use in NOGAPS-ALPHA and can be activated or deactivated as part of the model development process. The following sections describe new features in NOGAPS-ALPHA which are not, at present, part of the operational NWP model.

\subsection{Vertical Coordinate}

Designed primarily for tropospheric applications, the operational NOGAPS model currently uses a terrain-following $\sigma$ coordinate with 30 vertical levels (L30) extending from the surface to $1 \mathrm{hPa}$ ( $\sim 48 \mathrm{~km}$ altitude), as shown in Fig. 2a. Thermal and mechanical damping and enhanced horizontal spectral diffusion are applied to the top 2 full model layers to form a sponge layer (see orange half levels in Fig. 2a), which means that undamped operational output extends up to only the third full model level at $\sim 22 \mathrm{hPa}$.

To improve middle atmosphere simulations (Simmons and Burridge, 1981; Trenberth and Stepaniak, 2002), NOGAPSALPHA replaces the $\sigma$ coordinate with a hybrid $\sigma$ - $p$ vertical coordinate that transitions from terrain-following near the surface to pure pressure levels at $\sim 72.6 \mathrm{hPa}$ (Eckermann et al., 2004b). Figure $2 \mathrm{~b}$ demonstrates how this coordinate smoothly transitions model layer pressure height 
(a) Operational NOGAPS (2004)

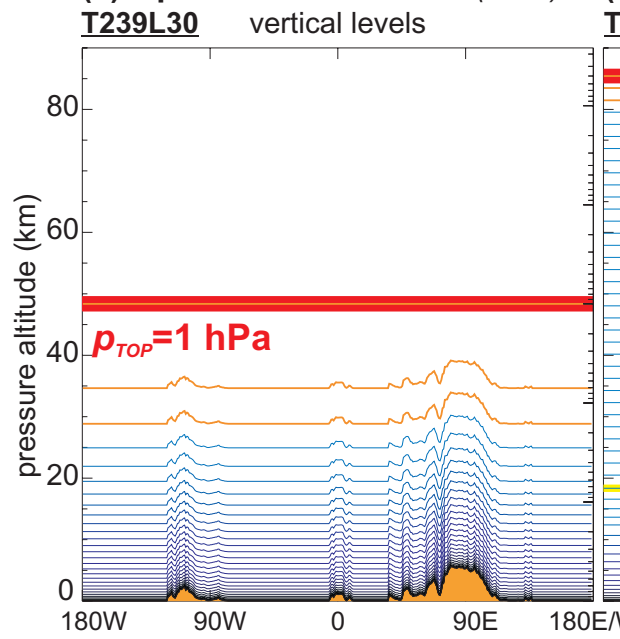

(b) NOGAPS-ALPHA (2004)

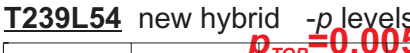

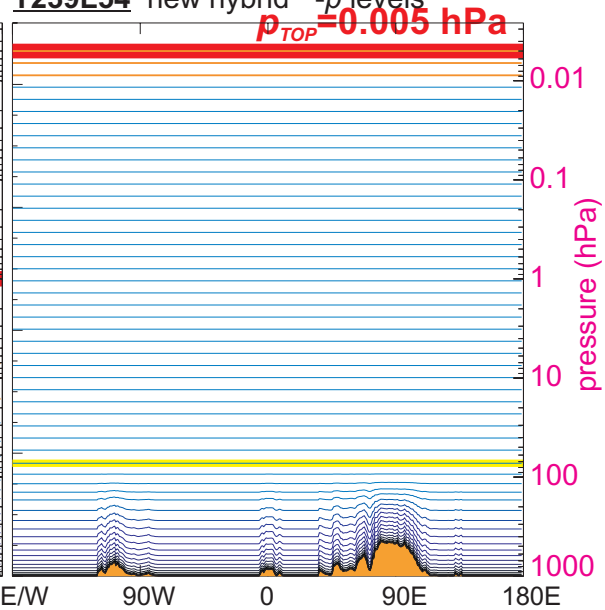

Fig. 2. Vertical levels around $34.5^{\circ} \mathrm{N}$ for: (a) operational NOGAPS 30 level (L30) model, with $p_{\text {top }}=1$ hPa; (b) new NOGAPS-ALPHA 54 level (L54) model with $p_{\text {top }}=0.005 \mathrm{hPa}$, using new hybrid $\sigma-p$ formulation with a first purely isobaric level at $72.6 \mathrm{hPa}$, shown in yellow. Top 3 model half levels (marked in orange) span the top 2 full model layers in NOGAPS where enhanced damping and diffusion act as a sponge layer.

thicknesses to constant thicknesses of $\sim 2 \mathrm{~km}$ in the stratosphere over arbitrary topography for our current 54 level NOGAPS-ALPHA formulation. This uniform vertical resolution throughout the middle atmosphere is similar to the current ECMWF model configuration and offers the prospect of better resolved middle atmosphere dynamics and transport.

\subsection{Radiation}

Raising the top boundary of the NOGAPS-ALPHA model requires an improved treatment of middle atmospheric radiative heating. To this end, we have replaced the operational model's current radiative heating scheme (Harshvardhan et al., 1987) with the CLIRAD longwave (Chou et al., 2001) and shortwave (Chou and Suarez, 2002) schemes, improving the net heating calculations at all levels but particularly in the middle atmosphere. Specifically, the updated CLIRAD shortwave heating rates include contributions from $\mathrm{O}_{2}$ and near-infrared $\mathrm{CO}_{2}$ bands that are not contained in the operational radiative heating scheme and led to underestimated peak shortwave heating in the middle atmosphere of as much as $1-2 \mathrm{~K} \mathrm{day}^{-1}$ (Eckermann et al., 2004b).

Shortwave heating and longwave cooling rates are currently computed using seasonally-varying two-dimensional (height-latitude) climatological ozone and water vapor mixing ratios. For NOGAPS-ALPHA, these values have been updated and extended vertically using the monthly mean ozone climatology of Fortuin and Kelder (1998) (1000$0.3 \mathrm{hPa}$ ) and Halogen Occultation Experiment (HALOE) water vapor measurements from $100-0.3 \mathrm{hPa}$ (Pumphrey et al., 1998). Above the $0.3 \mathrm{hPa}$ level, the ozone and water vapor mixing ratios are based on long-term climate output from NRL's CHEM2D model (McCormack and Siskind, 2002).

\subsection{Gravity Wave Drag}

Operational NOGAPS lacks any parameterization of middle atmospheric gravity wave drag (GWD). It is well-known that lack of GWD leads to, among other things, a cold bias in predicted wintertime Arctic stratospheric temperatures. As a result, operational NOGAPS temperatures tended to overpredict geographical regions of PSC formation during SOLVE2 (this cold bias should be borne in mind when interpreting Fig. 1). The extension of NOGAPS-ALPHA into the mesosphere should allow it to better simulate vertically deep diabatic descent through the vortex which can alleviate this cold bias, given sufficient resolution and good parameterizations of middle atmospheric GWD (Austin et al., 2003).

To this end, we have coded and implemented within NOGAPS-ALPHA four GWD schemes. These four schemes consist of two spectral GWD schemes for the middle atmosphere (Hines, 1997; Alexander and Dunkerton, 1999), a new orographic GWD scheme (Kim and Doyle, 2004 ${ }^{1}$ ) based to some extent on the work of Kim and Arakawa (1995), and a GWD parameterization scheme for convectively generated gravity waves based on Chun and Baik (2002). The performance of these schemes in NOGAPS-ALPHA forecast runs has not yet been rigorously tested. Therefore, the model calculations presented here utilize two different Rayleigh friction (RF) profiles applied to the zonal winds above $\sim 40 \mathrm{~km}$ (see Fig. 3). The first RF profile we used is a modification of a standard profile proposed by Lin and Williamson (2000) for dynamical core tests: their original profile and our mod-

\footnotetext{
${ }^{1}$ Kim, Y.-J. and J.D. Doyle: Offline evaluation of an orographic gravity wave drag scheme extended to include the effects of orographic anisotropy and flow blocking, Q. J. R. Meteorol. Soc., submitted, 2004.
} 
ified "deep" version are shown in Fig. 3 as profiles 2 and 3, respectively. This modified profile imposes very strong drag on the zonal winds in the upper stratosphere and mesosphere. The second profile we use (profile 4 in Fig. 3) is based on the "standard" RF profile used by Butchart and Austin (1998) in the UKMO Unified Model. It imposes less drag on the zonal winds, and is more representative of various profiles used in many global models that are also available for use in NOGAPS-ALPHA (Boville, 1986; Eckermann et al., 2004b). All NOGAPS-ALPHA simulations presented here used the Butchart and Austin (1998) RF profile. In addition, orographic GWD, specified using the Palmer et al. (1986) scheme, was applied from the surface up to $150 \mathrm{hPa}$. This is done to keep the orographic GWD scheme in NOGAPSALPHA consistent with the NOGAPS configuration that was operational during the SOLVE2 period.

Although the use of Rayleigh friction is a crude proxy for mesospheric GWD that can reduce realistic middle atmospheric variability (e.g. Shepherd et al., 1996; Lawrence, 1997), it's performance has been documented in previous global NWP and climate models (see, e.g., Shepherd et al., 1996; Butchart and Austin, 1998; Pawson et al., 1998). We have tested mesospheric Rayleigh friction in a 5-year freerunning simulation of an earlier low horizontal resolution T79L54 version of NOGAPS-ALPHA using the Rayleigh friction profile of Boville (1986) (profile 1 in Fig. 3). Figure 4 plots monthly averaged zonal-mean zonal winds for January, April, July, and October, which show reasonable agreement with climatological values (Randel et al., 2004). Figure 5 plots the mean meridional circulation computed as a mass flux from the residual mean mass stream function for January, April, July, and October. We see that, despite being designed primarily for short-term NWP, the NOGAPSALPHA middle atmosphere reproduces a realistic climatological Brewer-Dobson stratospheric circulation and a clear pole-to-pole mesospheric residual circulation.

\subsection{Upper Level Initialization}

NOGAPS-ALPHA is initialized here by combining archived operational output from FNMOC's Multivariate Optimum Interpolation (MVOI) system (up to $10 \mathrm{hPa}$ ) (Goerss and Phoebus, 1992) with an experimental "STRATOI" product (based on TOVS radiances) from 10-0.4 hPa. Above 0.4 $\mathrm{hPa}$, NOGAPS-ALPHA extrapolates the topmost initialization wind and temperature fields by progressively relaxing them with increasing altitude to climatological values from the 1986 COSPAR International Reference Atmosphere (CIRA) (Fleming et al., 1990). Given the unreliability of mesospheric CIRA winds during certain months, particularly near the equator (Randel et al., 2004), we have created an additional option of relaxing to climatological wind fields from the Upper Atmosphere Research Satellite (UARS) Reference Atmosphere Project (URAP) (Swinbank and Ortland, 2003). Final extrapolated temperature profiles are then used to spec-

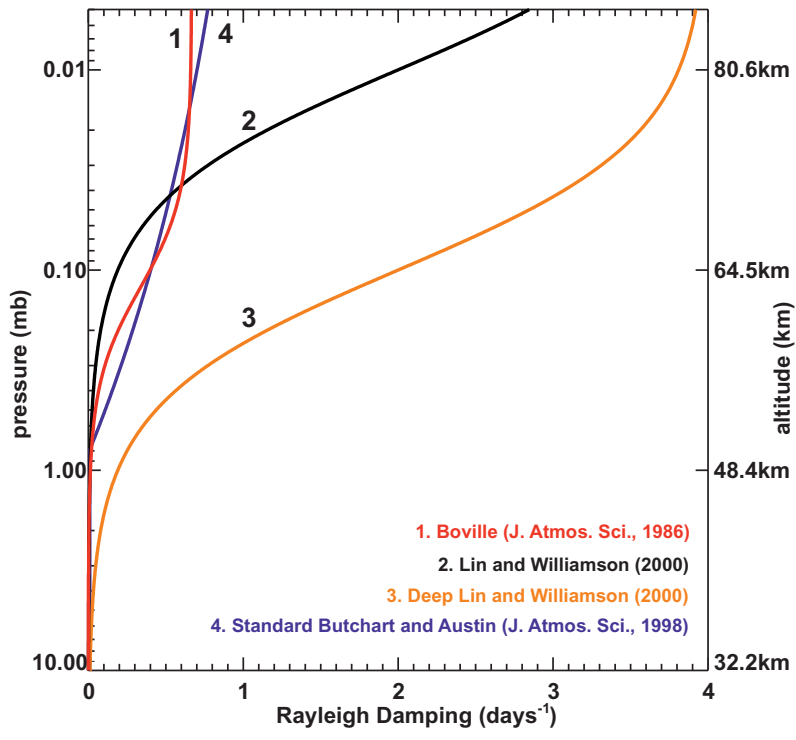

Fig. 3. Rayleigh friction profiles used in NOGAPS-ALPHA.

ify geopotential profiles using hydrostatic integration. For further details, see Eckermann et al. (2004b).

In late 2003, initialization of the operational NOGAPS model transitioned from MVOI to the NRL Variational Data Assimilation System (NAVDAS), which currently provides fields up to $\sim 4 \mathrm{hPa}$ (Daley and Barker, 2001; Goerss et al., 2003). NAVDAS began direct assimilation of AMSU-A radiance measurements in June 2004, providing additional motivation for development of a prognostic ozone scheme in NOGAPS-ALPHA.

\subsection{Prognostic Ozone}

A new three-dimensional (3D) prognostic ozone capability has been implemented in NOGAPS-ALPHA. Since FNMOC does not at present assimilate ozone, here for NOGAPSALPHA we use assimilated ozone fields from two different systems. The first is $2^{\circ} \times 2.5^{\circ}$ (latitude/longitude) analyzed 3D ozone mixing ratios from the GEOS data assimilation system, issued by NASA's Global Modeling and Assimilation Office (GMAO) (Stajner et al., 2001). The second is archived ozone initialization fields from the ECMWF IFS. Both assimilated ozone fields were interpolated to $1^{\circ} \times 1^{\circ}$ pressure-level fields for use in NOGAPS-ALPHA as an initialization field for ozone.

Two distinct prognostic ozone variables can be activated in NOGAPS-ALPHA. The first constituent represents "passive" ozone, where initialized ozone is subsequently subjected only to advection by the model's forecast meteorology. The second constituent, so-called "active" ozone, is subject to both advection and parameterized photochemical production and loss. The passive ozone tracer is a powerful tool for diagnosing model transport in the middle atmosphere. 

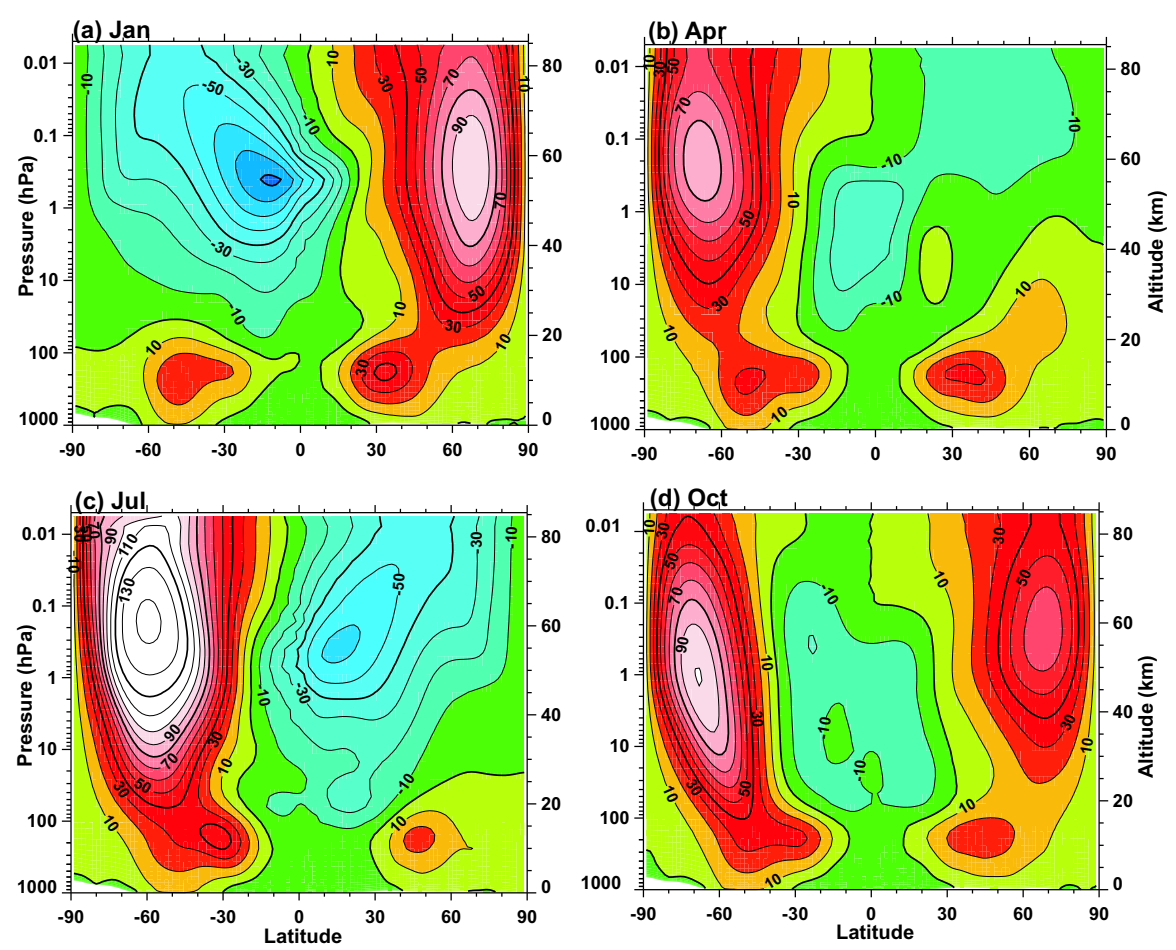

Fig. 4. Monthly zonal mean zonal winds from a 5-year T79L54 NOGAPS-ALPHA simulation for January, April, July, and October. Contours are drawn every $10 \mathrm{~ms}^{-1}$. Westerly winds are shaded yellow to red, easterly winds are shaded green to blue.
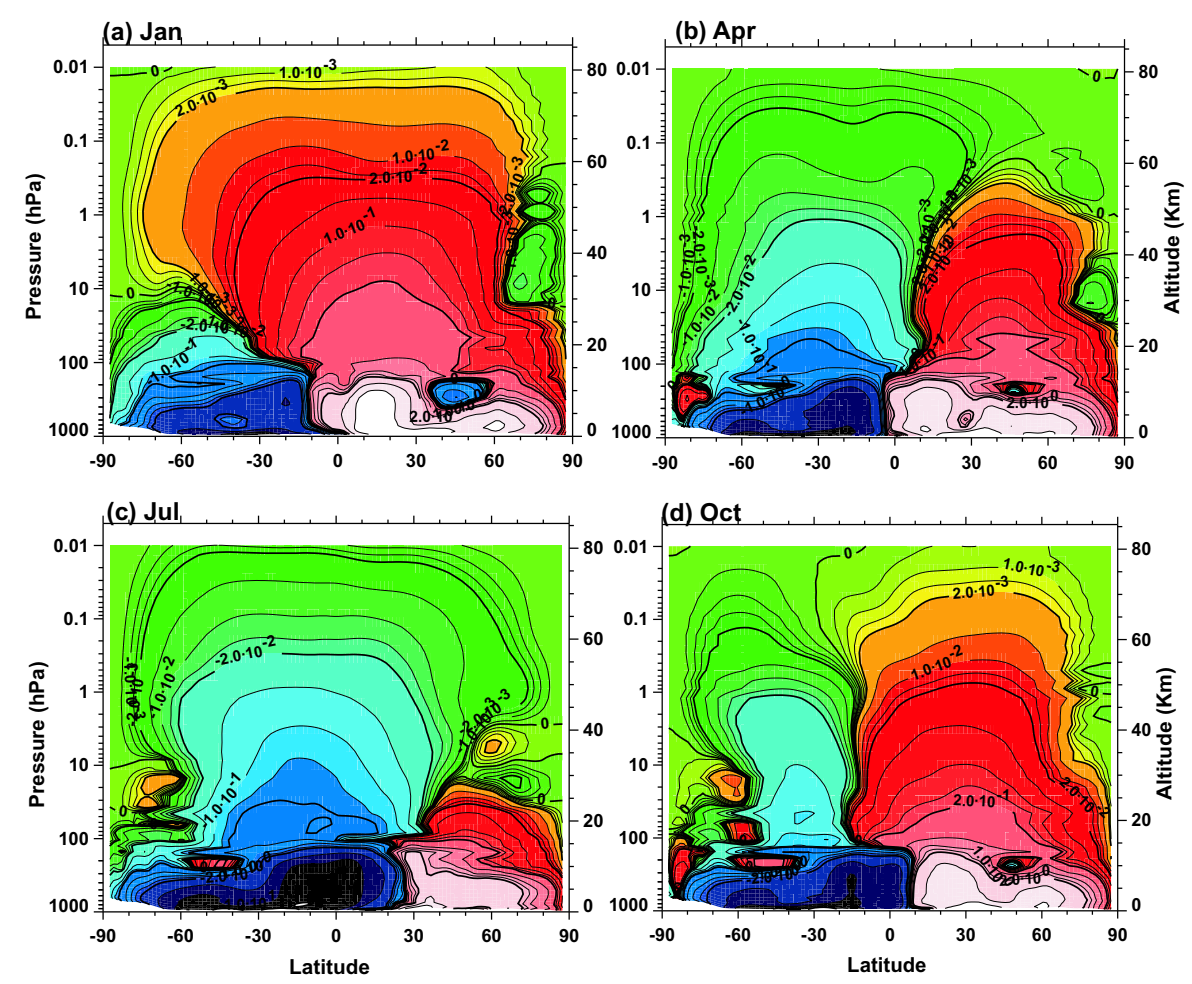

Fig. 5. Monthly mean meridional mass stream function from a 5-year T79L54 NOGAPS-ALPHA simulation for January, April, July, and October. Distance between contour lines is proportional to strength of mass flux. Clockwise circulation (positive contours) is shaded yellow to red, counter-clockwise circulation (negative contours) is shaded green to blue. Contour values are in units of $10^{10} \mathrm{~kg} \mathrm{~s}{ }^{-1}$. 
By taking the difference between active and passive ozone fields, one can distinguish between dynamical and photochemical variations in the model's three-dimensional global ozone fields.

These ozone fields are transported globally within NOGAPS-ALPHA using the same spectral advection algorithms used to advect meteorological variables such as vorticity and specific humidity. Over time, the spectral advection produces fine scale spectral noise in ozone mixing ratio fields (Rasch et al., 1990; Fairlie et al., 1994), which we effectively suppress by applying after each time step a small amount of $\nabla^{4}$ horizontal spectral diffusion, with a diffusion coefficient equal to that applied to the NOGAPS-ALPHA divergence fields. For the prognostic ozone fields reported here, spectral diffusion was applied to the isobaric stratospheric layers only.

Since NOGAPS-ALPHA is designed to be a forecast model, calculating the ozone production and loss terms using a complete photochemical model is too computationally expensive at present. Instead, the net ozone photochemical production/loss rates, $(P-L)$, can be parameterized as follows. First, we approximate net production/loss to be a function of three variables: the current local ozone mixing ratio $(r)$, local temperature $(T)$, and the overlying ozone column abundance $(\Sigma)$ (Cariolle and Déqué, 1986; McLinden et al., 2000). By approximating this functional dependence using a truncated (linearized) Taylor Series expansion, the ozone photochemical tendency equation can then be expressed as follows:

$$
\begin{aligned}
\frac{d r}{d t} & =(P-L)_{o}+\left.\frac{\partial(P-L)}{\partial r}\right|_{o}\left[r-r_{o}\right] \\
& +\left.\frac{\partial(P-L)}{\partial T}\right|_{o}\left[T-T_{o}\right]+\left.\frac{\partial(P-L)}{\partial \Sigma}\right|_{o}\left[\Sigma-\Sigma_{o}\right],
\end{aligned}
$$

where $d / d t$ is the advective time derivative, so that when the right hand side of (1) is zero, we reproduce passive ozone. The photochemical coefficients $(P-L)_{o},\left.\frac{\partial(P-L)}{\partial r}\right|_{o}$, $\left.\frac{\partial(P-L)}{\partial T}\right|_{o}$, and $\left.\frac{\partial(P-L)}{\partial \Sigma}\right|_{o}$ represent diurnally-averaged quantities computed at a reference state $\left(r_{o}, T_{o}, \Sigma_{o}\right)$ which is ideally the photochemical equilibrium state, but when implemented as a model parameterization is usually in practice a 2D observed climatological state for each variable (McLinden et al., 2000; Dethof and Holm, 2002). These photochemical coefficients are computed offline using a 2D (altitudelatitude) photochemical model with complete descriptions of radiation and constituent photochemistry. The partial derivative terms are estimated by varying the one variable while keeping the other two reference variables constant and then estimating the derivative by linear fits to the change in production/loss (McLinden et al., 2000). Their values are tabulated as functions of altitude and latitude for each month of the year. Currently NOGAPS-ALPHA applies the ozone photochemistry schemes up to $\sim 1 \mathrm{hPa}$, then smoothly re-
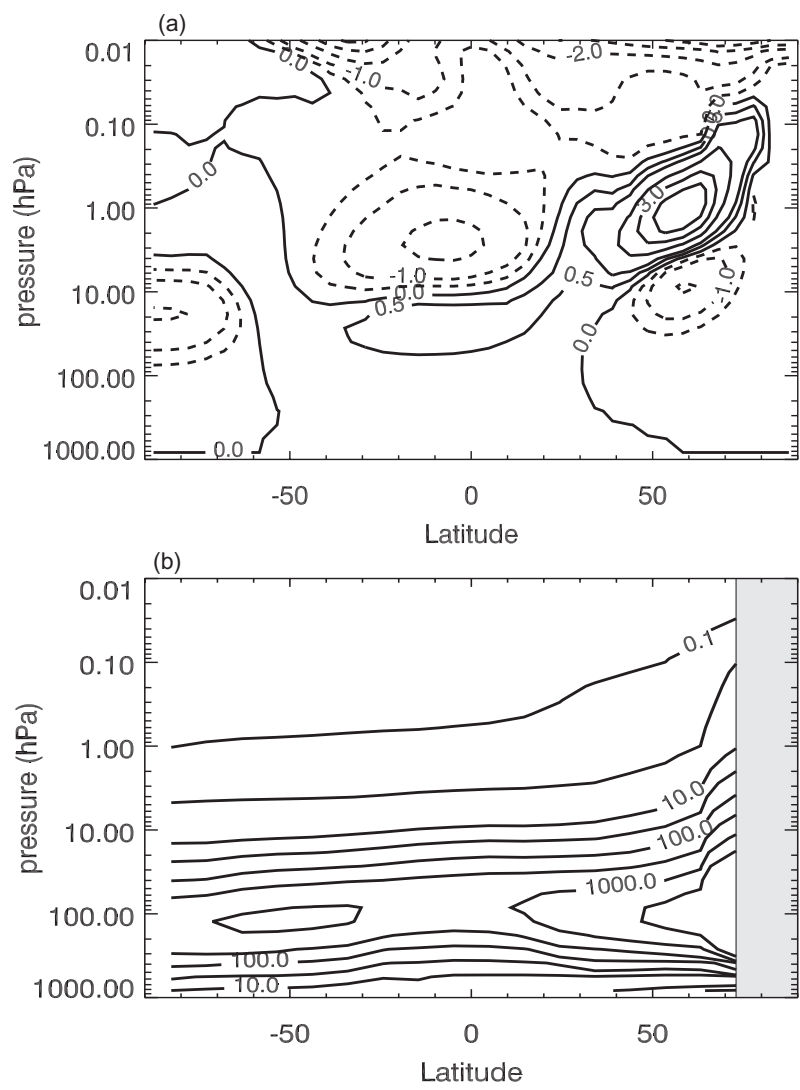

Fig. 6. Values of (a) the residual net ozone mixing ratio tendency $(P-L)_{o}$ in ppmv month ${ }^{-1}$, and $(\mathbf{b})$ photochemical relaxation time $\tau_{\mathrm{O}_{3}}$ (in days) computed for mid-January conditions with the NRL CHEM2D model. Shaded region in (b) indicates polar night.

laxes the active ozone fields to $2 \mathrm{D}$ climatological mixing ratios in the mesosphere.

Section 4 compares results from three different linearized photochemistry parameterizations in order to determine the sensitivity of the prognostic ozone simulations to the details of the parameterization coefficients. Specifically, we compare NOGAPS-ALPHA "active" ozone fields computed using the Cariolle and Déqué (1986) coefficients (hereafter CD86), the McLinden et al. (2000) "LINOZ" coefficients (hereafter LINOZ), and coefficients from the NRL CHEM2D model (hereafter CHEM2D). Note that the CHEM2D scheme currently employs only the first two terms on the right hand side of (1), representing the residual net production/loss $(P-L)_{o}$ and the sensitivity to changes in local ozone mixing ratio, $\left.\frac{\partial(P-L)}{\partial r}\right|_{o}$, respectively. The latter term is often expressed in terms of the photochemical relaxation time for ozone, $\tau_{\mathrm{O}_{3}}=-\left[\left.\frac{\partial(P-L)}{\partial r}\right|_{o}\right]^{-1}$. Figure 6 plots $(P-L)_{o}$ and $\tau_{\mathrm{O}_{3}}$ calculated with the NRL CHEM2D model for mid-January conditions. The very small residual tendency $(P-L)_{o}$ and very long relaxation times $\tau_{\mathrm{O}_{3}}$ at high Northern winter latitudes indicate that transport effects should generally dominate over photochemistry during the 
SOLVE2 campaign. However, the ozone simulations in Section 4 demonstrate that stratospheric ozone forecast skill in this region can be sensitive to the treatments of both photochemistry and transport.

\section{Data description}

As a first test of the new NOGAPS-ALPHA model performance, we compare simulations of stratospheric ozone and temperature for select periods during the SOLVE2 campaign with observations from a variety of sources. These sources include operational ECMWF meteorological analyses, satellite-based measurements of the total ozone column abundance and ozone profiles, and data records from instruments aboard the NASA DC-8 aircraft. A short description of each data source follows.

\subsection{Meteorological analyses}

During the SOLVE2 period, operational NOGAPS analyses from the MVOI system (Goerss and Phoebus, 1992) were issued at $0,6,12$, and $18 \mathrm{Z}$. These gridded $\left(1^{\circ} \times 1^{\circ}\right.$ latitude/longitude) fields include horizontal winds, temperature, geopotential height, dew point depression, vorticity, and divergence on a fixed set of pressure levels extending up to $10 \mathrm{hPa}$. In addition, 6-hourly high-resolution (T511L60) operational analyses from the ECMWF IFS provided winds, temperature, geopotential height, vorticity, divergence, and ozone mass mixing ratio (ECMWF, 1995). The ECMWF fields are issued on native model levels (see, e.g. Dethof, 2003) and a reduced (N256) Gaussian grid. For both the 14 January and 21 January case studies in the present work, (Cases 1 and 2 respectively) operational T239L30 NOGAPS and T511L60 ECMWF meteorological analyses are used to help assess the performance of the new NOGAPS-ALPHA model.

NOGAPS-ALPHA ozone simulations use 3D stratospheric ozone analyses output from either the NASA GEOS4 data assimilation system or the ECMWF IFS to initialize both the active and passive ozone fields (see Sect. 2.6).

Daily global GEOS4 ozone analyses at $0 \mathrm{Z}$ were issued throughout the SOLVE2 winter at fixed pressure levels from $1000 \mathrm{hPa}$ to $0.2 \mathrm{hPa}$ with a $2^{\circ} \times 2.5^{\circ}$ latitude/longitude resolution. The GEOS4 system assimilates stratospheric ozone profiles and total ozone column measurements from the NOAA-16 SBUV/2 instrument. Ozone photochemical production and loss rates are specified as functions of latitude, pressure, and month (Fleming et al., 2001), with adjustments to the upper stratospheric values as in Stajner et al. (2004).

The operational ECMWF ozone assimilation (Dethof, 2003) product is based on NOAA-16 SBUV/2 profile and ERS-2 GOME total ozone measurements and uses the linearized ozone photochemistry scheme of Cariolle and Déqué (1986).

\subsection{Satellite ozone measurements}

The present study compares NOGAPS-ALPHA prognostic ozone simulations with measurements of the integrated column ozone abundance from the Total Ozone Mapping Spectrometer (TOMS) aboard the NASA Earth Probe satellite (McPeters et al., 1998), hereafter referred to as EPTOMS. Since the largest contribution to the total ozone column originates in the lower stratosphere, where the ozone photochemistry is slow compared to transport, this quantity provides a good test of the model's spectral transport.

Observations of the vertical distribution of ozone come from the NASA Stratospheric Aerosol and Gas Experiment (SAGE) III instrument aboard the METEOR-3M satellite (Thomason and Taha, 2003), and from the NRL Polar Ozone and Aerosol Monitoring (POAM) III instrument aboard the CNES SPOT-4 satellite (Bevilacqua et al., 2002). Both satellites operate in sun-synchronous orbits that offer good coverage of polar latitudes during winter. For the 11-22 January 2003 period, SAGE III provided 13 to 14 profiles each day over latitudes ranging from $67^{\circ} \mathrm{N}-69^{\circ} \mathrm{N}$. The present study uses the Version 3.04 "least squares" SAGE III retrievals between $200-1 \mathrm{hPa}$. For the same time period, POAM III provided 14 to 15 stratospheric profiles (Version 3) each day from $250-0.1 \mathrm{hPa}$ over the $64^{\circ} \mathrm{N}-65^{\circ} \mathrm{N}$ latitude range. The combined random and systematic errors in the stratospheric ozone profiles are $<5 \%$ for both instruments. Both SAGE III and POAM III retrievals provide profiles of ozone molecular concentration that are converted to volume mixing ratio using temperature and pressure analyses. SAGE III retrievals use temperature and pressure information from the National Centers for Environmental Prediction (NCEP) up to $1 \mathrm{hPa}$. POAM III retrievals use temperature and pressure information provided by the United Kingdom Meteorological Office (UKMO). Section 4 compares NOGAPS-ALPHA ozone hindcasts for 11-16 January 2003 (Case 1) with EPTOMS, SAGE III, and POAM III observations as well as ECMWF operational ozone analyses and forecasts.

\subsection{DC-8 measurements}

Of the 14 different experiments on the NASA DC-8 aircraft payload for SOLVE2, two are particularly well-suited for comparison with NOGAPS-ALPHA simulations. The first experiment is the NASA Langley Differential Absorption Lidar (DIAL). DIAL measures backscattered radiation near wavelengths of $301 \mathrm{~nm}$ and $311 \mathrm{~nm}$, providing (among other things) in-flight ozone profiles with a vertical resolution of $750 \mathrm{~m}$ over the altitude region from $\sim 1 \mathrm{~km}$ above the aircraft up to $22-26 \mathrm{~km}$ under ideal conditions (Grant et al., 2003). The second experiment is the NASA Goddard Airborne Raman Ozone Temperature and Aerosol Lidar (AROTAL). AROTAL uses a combination of Rayleigh and Raman backscattered radiation at $355 \mathrm{~nm}$ to retrieve temperature profiles up to $60 \mathrm{~km}$ with a vertical resolution of 0.5 
$1.5 \mathrm{~km}$ (Burris et al., 2002). This instrument also utilizes a differential absorption technique to obtain ozone profiles up to $\sim 30 \mathrm{~km}$, even in the presence of aerosols and clouds. Section 5 presents a combination of both DIAL and AROTAL ozone profiles as a means of validating high resolution T239 NOGAPS-ALPHA prognostic ozone simulations along individual DC-8 flight tracks during the 21 January 2003 stratospheric warming case (i.e. Case 2).

\section{Case 1: 11-16 January 2003}

\subsection{Description}

As Fig. 1 shows, $30 \mathrm{hPa}$ temperatures over the polar region were cold enough for PSCs to form during the early winter of 2002-2003. The DC-8 flight on 14 January 2003 was the last to take place before the stratospheric warming event in mid-January (see Fig. 1 and Sect. 5). During the 14 January flight, instruments aboard the DC-8 detected a small region of PSCs over the southern tip of Scandinavia.

Figure 7a plots NOGAPS MVOI analyses of $30 \mathrm{hPa}$ temperatures and geopotential heights on 14 January 2003 at $0 \mathrm{Z}$. The region where PSCs were detected lies within a larger synoptic-scale area of cold temperatures. Figure $7 \mathrm{~b}$ plots the corresponding temperatures and heights at $300 \mathrm{hPa}$, showing a pronounced anti-cyclonic feature over Western Europe. This type of feature produces a combination of upward vertical motion and quasi-isentropic horizontal transport in the lowermost stratosphere, leading to a divergence of ozonerich air out of the column (see, e.g. Rood et al., 1992; Orsolini et al., 1995). These localized, reversible occurrences of low total ozone, often referred to as extreme ozone minima or ozone "mini-holes", are common occurrences with the passage of an intense upper tropospheric anticyclone (Newman et al., 1988; McCormack and Hood, 1997; James, 1998). In certain cases, the resulting adiabatic cooling in the lower stratosphere can be sufficiently strong to produce temperatures below $195 \mathrm{~K}$, which is a typical threshold temperature for the formation of nitric acid trihydrate (NAT) particles that constitute Type I PSCs (Teitelbaum et al., 2001; WMO, 2003).

Figure 8 plots total ozone column measurements from the NASA EPTOMS instrument on 14 January 2003. The heavy red contour highlights the total ozone minimum near $10^{\circ} \mathrm{W}-$ $30^{\circ} \mathrm{E}$ where total ozone values fall below 235 Dobson units (DU). This region coincides with the minimum in $30 \mathrm{hPa}$ temperatures and maximum in $300 \mathrm{hPa}$ geopotential heights shown in Fig. 7. Conditions on 14 January 2003 provide a good first test of the ability of NOGAPS-ALPHA to simulate this interaction between tropospheric and stratospheric dynamics and its impact on the ozone distribution.

To determine the sensitivity of the model ozone simulations to the linearized photochemistry parameterization, we conducted a series of low-resolution $\mathrm{T} 79\left(\sim 1.5^{\circ}\right.$ lati- (a) NOGAPS $30 \mathrm{hPa}$ : 2003011400

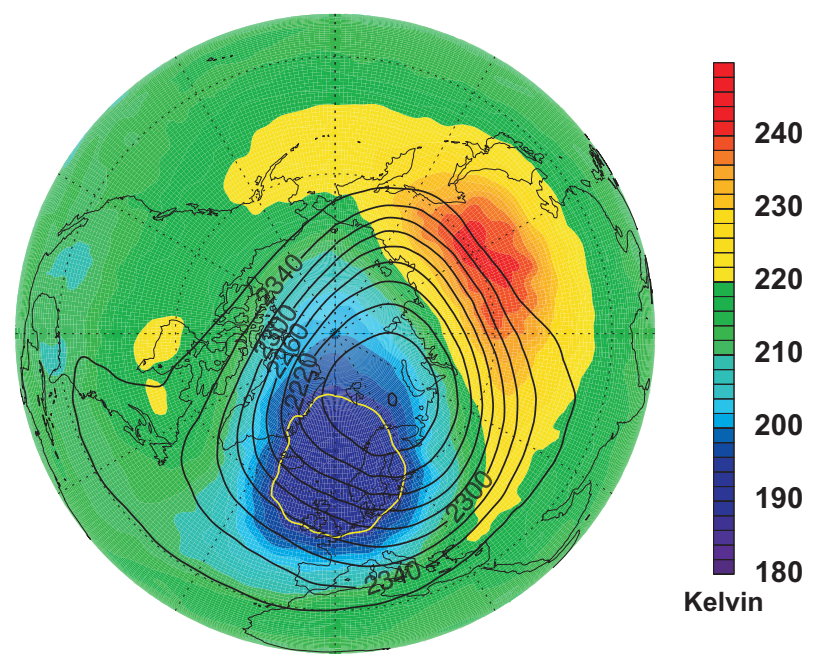

(b) NOGAPS $300 \mathrm{hPa}$ : 2003011400

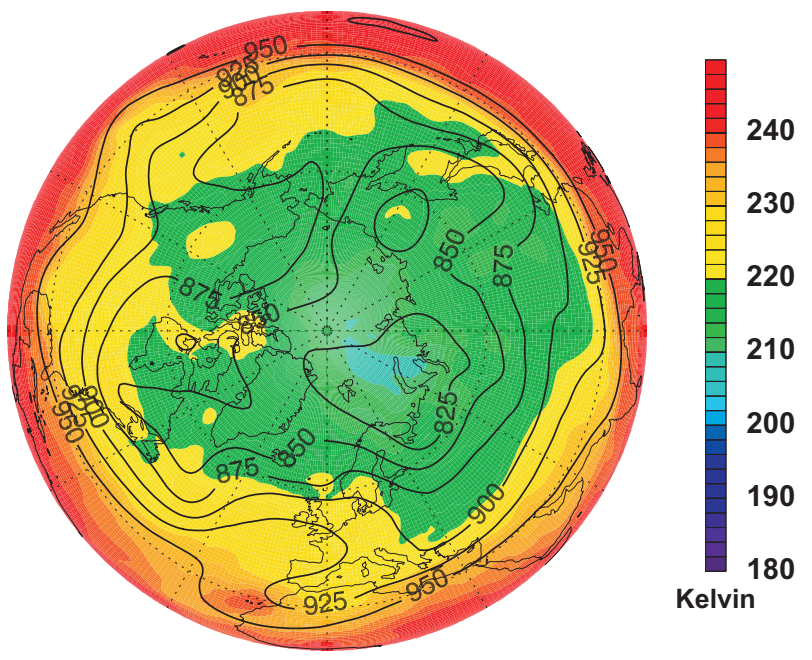

Fig. 7. Operational $1^{\circ} \times 1^{\circ}$ NOGAPS MVOI analyses of geopotential height in dam (solid contours) and temperature in Kelvin (colors) on 14 January 2003 at $0 \mathrm{Z}$ for (a) $30 \mathrm{hPa}$ and (b) $300 \mathrm{hPa}$. $30 \mathrm{hPa}$ temperatures below $195 \mathrm{~K}$ are enclosed with a yellow contour. Polar projection extends to $20^{\circ} \mathrm{N}$.

tude/longitude spacing) simulations using three different sets of linearized photochemistry coefficients. These include the most recent version of the CD86 scheme, currently used in the ECMWF IFS (H. Teyssedre, personal communication), the LINOZ scheme, and the NRL CHEM2D scheme (see Sect. 2.6 for details). Our goal is to determine which scheme most closely reproduces the observed 3D ozone distribution poleward of $20^{\circ} \mathrm{N}$ over the period 11-16 January 2003 .

\subsection{Comparison with ozone analyses}

For each simulation, both active and passive ozone fields were initialized using ozone mixing ratio analyses from the 


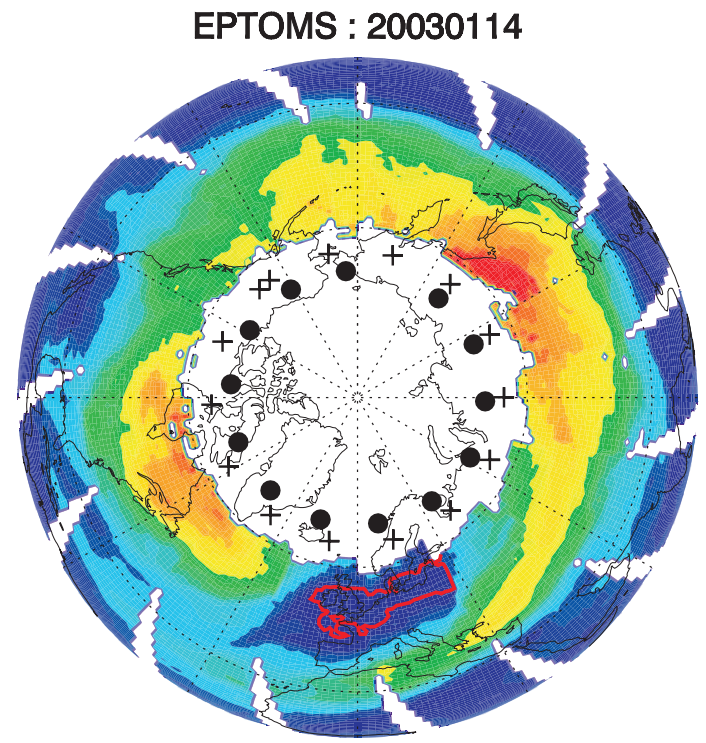

500
200
250
250
400
400
$D^{2}$

Fig. 8. EPTOMS total ozone on 14 January 2003. Polar projection extends to $20^{\circ} \mathrm{N}$. White areas denote missing data. Heavy red contour encloses area where total ozone column abundance is below 235 Dobson units (DU). Locations of POAM III (crosses) and SAGE III (circles) ozone profile measurements on this date are also indicated.

NASA GEOS4 system (Stajner et al., 2001, 2004). Figure 9a plots the initial NOGAPS-ALPHA active/passive ozone mixing ratios as a function of pressure and longitude at $64.9^{\circ} \mathrm{N}$ on 11 January 2003 at $0 \mathrm{Z}$. At this latitude, the initial NOGAPS-ALPHA (GEOS4) ozone distribution differs substantially from the ECMWF ozone analyses for the same day and same location plotted in Fig. 9b. Specifically, the ECMWF ozone mixing ratios exceed the NASA GEOS4 mixing ratios by more than 2 ppmv between $30^{\circ} \mathrm{W}-30^{\circ} \mathrm{E}$. Figure $9 \mathrm{c}$ shows a series of ozone mixing ratio profiles from the POAM III instrument on 11 January 2003. The POAM III measurements confirm the presence of low ozone mixing ratios between $30^{\circ} \mathrm{W}-30^{\circ} \mathrm{E}$ that are not captured in the ECMWF analysis.

This discrepancy between the GEOS4 and ECMWF ozone analyses over the North Atlantic sector is common throughout the SOLVE2 period poleward of $\sim 60^{\circ} \mathrm{N}$; at lower latitudes, however, both the ECMWF and GEOS4 ozone products are in good agreement. It has been pointed out by an anonymous referee that the ECMWF system (Dethof, 2003) only assimilates SBUV/2 and GOME satellite ozone observations between $40^{\circ} \mathrm{S}$ and $40^{\circ} \mathrm{N}$, whereas the NASA GEOS4 system (Stajner et al., 2001) incorporates SBUV/2 observations at all available latitudes in its analysis. This fact may explain the large differences between the GEOS4 and ECMWF ozone analyses at high northern latitudes during the SOLVE2 campaign whenever the local ozone distribution exhibited large deviations from climatological values.
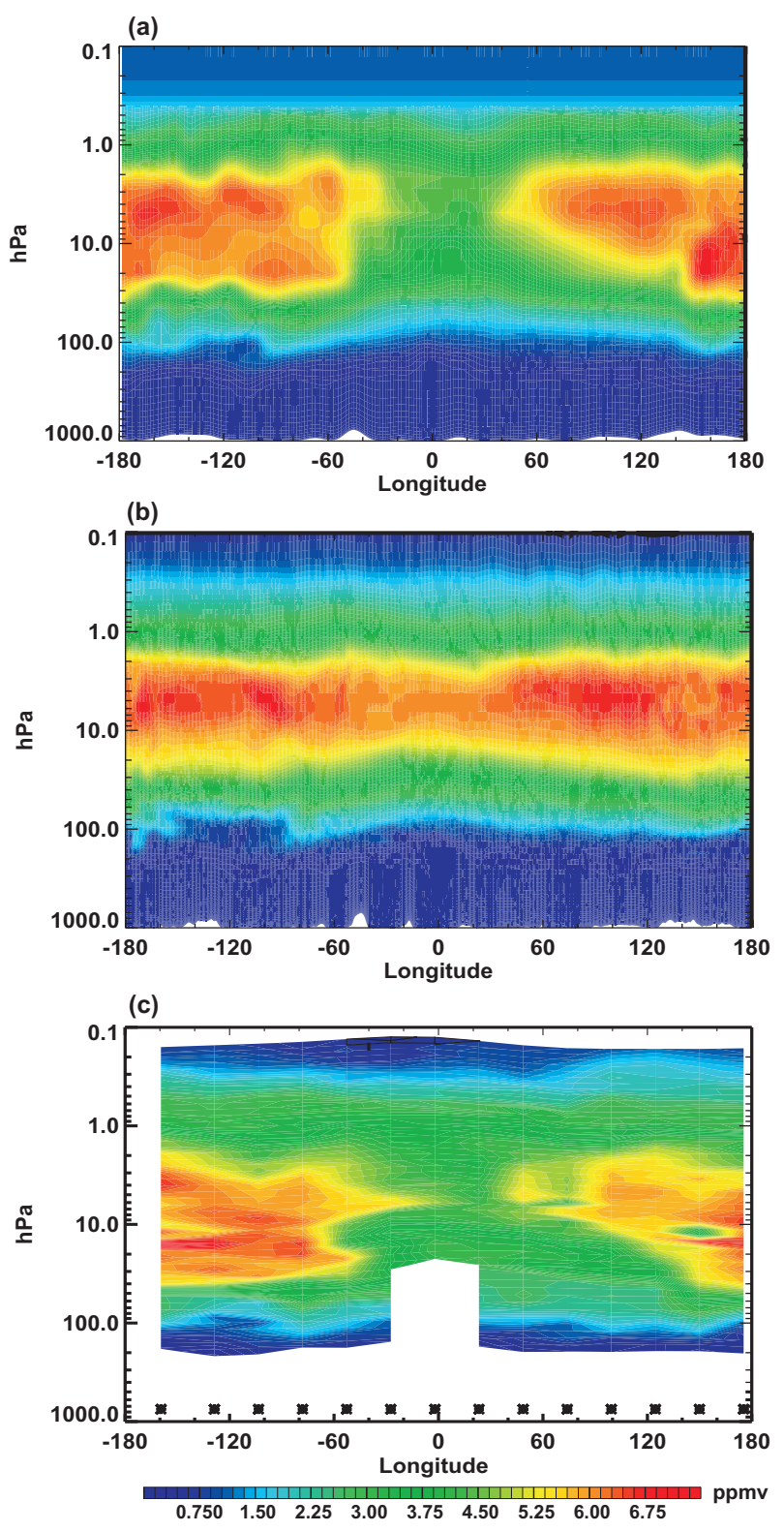

Fig. 9. (a) Ozone mixing ratios (ppmv) from the 11 January 2003 NASA GEOS4 analyses at $0 \mathrm{Z}$ and $64.9^{\circ} \mathrm{N}$; (b) ozone mixing ratios from 11 January 2003 operational ECMWF analyses at $0 \mathrm{Z}$ and $64.4^{\circ} \mathrm{N}$; (c) POAM III ozone mixing ratio measurements at $64.2^{\circ} \mathrm{N}$ on 11 January 2003, with asterisks indicating latitude of individual POAM profiles and white areas indicating missing data.

\subsection{NOGAPS-ALPHA O O hindcasts: 11-16 January 2003}

Figure 10 plots NOGAPS-ALPHA profiles of prognostic ozone for a 5-day simulation initialized on 11 January 2003 at $0 \mathrm{Z}$ over Kiruna, Sweden $\left(68^{\circ} \mathrm{N}, 20^{\circ} \mathrm{E}\right)$. This location was chosen for its proximity to both the lowest total ozone values on 14 January and the measurement latitudes of the SAGE III and POAM III instruments (see Fig. 8). Each plot compares the passive ozone (dashed black curve) with active 

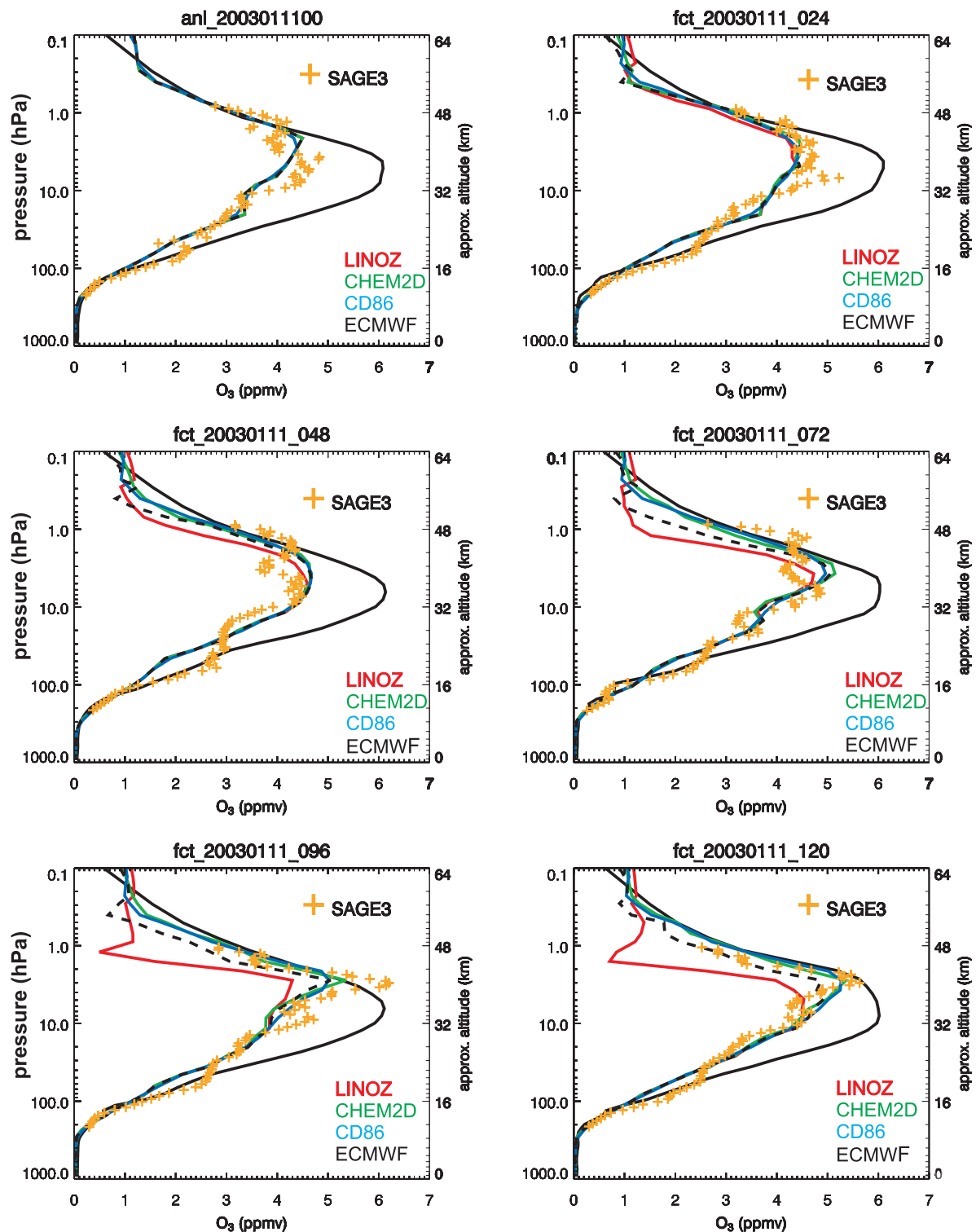

Fig. 10. NOGAPS-ALPHA ozone mixing ratio profiles over Kiruna, Sweden $\left(68^{\circ} \mathrm{N}, 20^{\circ} \mathrm{E}\right)$ for a 5 -day forecast initialized on $11 \mathrm{January}$ 2003 at $0 \mathrm{Z}$ using the CD86 (blue), LINOZ (red), and CHEM2D (green) photochemistry schemes. NOGAPS-ALPHA passive ozone is plotted as a dashed black curve. Co-located SAGE III profiles are plotted as orange symbols. The solid black curve denotes the corresponding ECMWF ozone analysis and forecasts initialized on 11 January 2003.

ozone computed using the CD86 coefficients (blue curve), the LINOZ coefficients (red curve), and the CHEM2D coefficients (green curve). Also included in Fig. 10 are the ECMWF IFS ozone forecasts (solid black curve) and colocated ozone profiles from the SAGE III instrument (points) for each day. As Fig. 10 shows, the differences between the GEOS4 and ECMWF ozone initializations at this location on 11 January 2003 explain why the ECMWF ozone forecasts over the 5-day period disagree with the NOGAPS-ALPHA simulations and with the independent SAGE III measurements between $50-1 \mathrm{hPa}$. Interestingly, the ECMWF ozone profiles between $100-50 \mathrm{hPa}$ in Fig. 10 show better agreement with the SAGE III observations than corresponding
NOGAPS-ALPHA ozone profiles throughout the 120-hour period. The altitude dependence of the ECMWF IFS ozone ozone forecast skill is discussed further in Section 5.

A comparison of the active ozone simulations (blue, red, and green curves in Fig. 10) shows all three photochemistry schemes exhibit little difference with the passive ozone profile below $\sim 10 \mathrm{hPa}$. In this altitude region, there is generally good agreement among the three different active ozone schemes, passive ozone, and observed ozone profiles from both the SAGE III and POAM III instruments. This is to be expected since ozone photochemistry is slow compared to transport below $\sim 10 \mathrm{hPa}$ (see Fig. 6). 
Above $\sim 10 \mathrm{hPa}$, however, differences emerge between the active and passive ozone values, and between the individual active ozone simulations as well. The differences between the CD86 and CHEM2D results after 5 days are very small, and they are both in good agreement with the SAGE III measurements shown in Fig. 10. The similarity between the CHEM2D and CD86 profiles in Fig. 10 demonstrates that neglecting the temperature and column terms in Eq. (1) have a minor impact on the model ozone over 5 days at high latitudes in winter. In contrast, the LINOZ scheme produces excessive ozone loss that is in disagreement with the available SAGE III profiles, POAM III profiles (not shown), and with the NOGAPS-ALPHA simulations using CHEM2D and CD86 photochemistry schemes.

The low upper stratospheric ozone mixing ratios in the NOGAPS-ALPHA simulation using the LINOZ scheme (red curve in Fig. 10) appear to be a consequence of unrealistically large negative values in the LINOZ scheme's $(P-L)_{o}$ term. As Fig. 6 illustrates, the magnitude of the net ozone mixing ratio tendency $\left|(P-L)_{o}\right|$ at high northern latitudes during January is typically small, $<1$ ppmv month ${ }^{-1}$, above $10 \mathrm{hPa}$ and poleward of $60^{\circ} \mathrm{N}$. In comparison to both the CD86 and CHEM2D coefficients, the LINOZ $\left|(P-L)_{o}\right|$ term is $5-10$ times larger at all latitudes above $\sim 10 \mathrm{hPa}$ for all months. The underlying cause for the excessive LINOZ ozone loss above $10 \mathrm{hPa}$ may be related to an overestimation of the background ozone mixing ratios in the model (McLinden et al., personal communication, 2004). Overall, the results from the initial NOGAPS-ALPHA prognostic ozone simulations indicate that the LINOZ photochemistry parameterization may not be appropriate for upper stratospheric applications.

Figure 11 plots NOGAPS-ALPHA model ozone mixing ratio profiles at $65^{\circ} \mathrm{N}$ and $135^{\circ} \mathrm{E}$ from the same 5-day simulation beginning 11 January 2003 at $0 \mathrm{Z}$. Here we compare results from the three different ozone photochemistry schemes, passive ozone, the ECMWF ozone forecasts, and POAM III ozone profiles. Unlike the previous case, the initial NOGAPS-ALPHA ozone mixing ratio profiles and ECMWF operational ozone analyses on 11 January over this location are in good agreement. Total ozone values on 14 January (forecast hour 96) were $>475$ DU over this location, and the flow at mid-stratospheric levels (see Fig. 7) brought air from lower sunlit latitudes poleward. Thus the ozone photochemistry parameterization should have more of an impact on the ozone profiles at this location than for the ozone profiles over Kiruna (see Fig. 10) where mid-stratospheric air was largely confined within polar night.

As Fig. 11 shows, the NOGAPS-ALPHA ozone simulations using the LINOZ scheme again produce excessive ozone loss above $10 \mathrm{hPa}$ over the course of 2-3 days. However, significant differences can also be seen between the results from the CD86 and CHEM2D schemes. By hour 96, both the CD86 results and the ECMWF operational ozone forecasts (which use the CD86 scheme) produce ozone mixing ratios between $10 \mathrm{hPa}$ and $50 \mathrm{hPa}$ that are up to 2 ppmv less than values from either the CHEM2D or LINOZ schemes or the model passive ozone. Above $10 \mathrm{hPa}$, the LINOZ scheme again produces excessive ozone loss as compared to the POAM profiles. Both CHEM2D and passive ozone profiles agree well with POAM observations, especially at hours 96 and 120 .

For the ozone simulations over $65^{\circ} \mathrm{N}$ and $135^{\circ} \mathrm{E}$ shown in Fig. 11, the initial NOGAPS-ALPHA and ECMWF ozone profiles agree quite well. Over time, differences emerge between the NOGAPS-ALPHA simulations and ECMWF forecasts due to different values of the photochemical relaxation time $\tau_{\mathrm{O}_{3}}=-\left[\left.\frac{\partial(P-L)}{\partial r}\right|_{o}\right]^{-1}$. in the lower stratosphere (see Eq. 1). At this location, the model ozone mixing ratios exceed 2-D climatological values $\left(r_{o}\right)$ and so the ozone tendency is negative. Typically, values of $\tau_{\mathrm{O}_{3}}$ exceed 100 days in the midlatitude stratosphere near $25 \mathrm{~km}$ (Brasseur and Solomon, 1986). In the CD86 scheme (see, e.g. Cariolle and Déqué, 1986, their Fig. 3), these values are 30-50 days. The shorter relaxation times of the CD86 scheme cause lower stratospheric ozone mixing ratios at midlatitudes to relax back to climatology 2-3 times faster than in either the CHEM2D or LINOZ schemes. Note that both the ECMWF and NOGAPS-ALPHA model ozone exhibit the same tendency toward lower ozone when the latter model employs the CD86 scheme, the same scheme currently used in the operational ECMWF IFS.

Next, three high resolution T239 NOGAPS-ALPHA simulations were conducted over the same 5-day period starting on 11 January 2003. The T239 configuration, with an approximate horizontal resolution of $0.5^{\circ}$, matches the current operational NOGAPS configuration and is currently the best formulation to capture detailed structure in long-lived tracers. Here we compare NOGAPS-ALPHA T239 total ozone fields with total ozone fields derived from operational T511 ECMWF IFS forecasts. The largest contribution to the total ozone column abundance comes from the lower stratosphere (i.e. $10-20 \mathrm{~km}$ altitude), where transport effects tend to dominate over photochemistry. By using ozone photochemistry and initial conditions similar to the operational ECMWF model, and relaxing back to the same $2 \mathrm{D} \mathrm{O}_{3}$ climatology, we can attempt to reproduce the ECMWF total ozone distribution and in doing so determine the extent to which model transport can explain the differences shown in Figs. 10 and 11.

Figure 12a plots the total ozone distributions at hour 96, valid at $0 \mathrm{Z} 14$ January 2003, computed from NOGAPSALPHA prognostic ozone using the CHEM2D photochemistry scheme and initialized with the NASA GEOS4 operational ozone analyses. This NOGAPS-ALPHA total ozone field exhibits very good qualitative and quantitative agreement with the EPTOMS total ozone distribution for 14 January (Fig. 8). Specifically, the NOGAPS-ALPHA total ozone in Fig. 12a reproduces the regions of low total ozone $(<235 \mathrm{DU})$ over the North Atlantic sector, high total ozone 

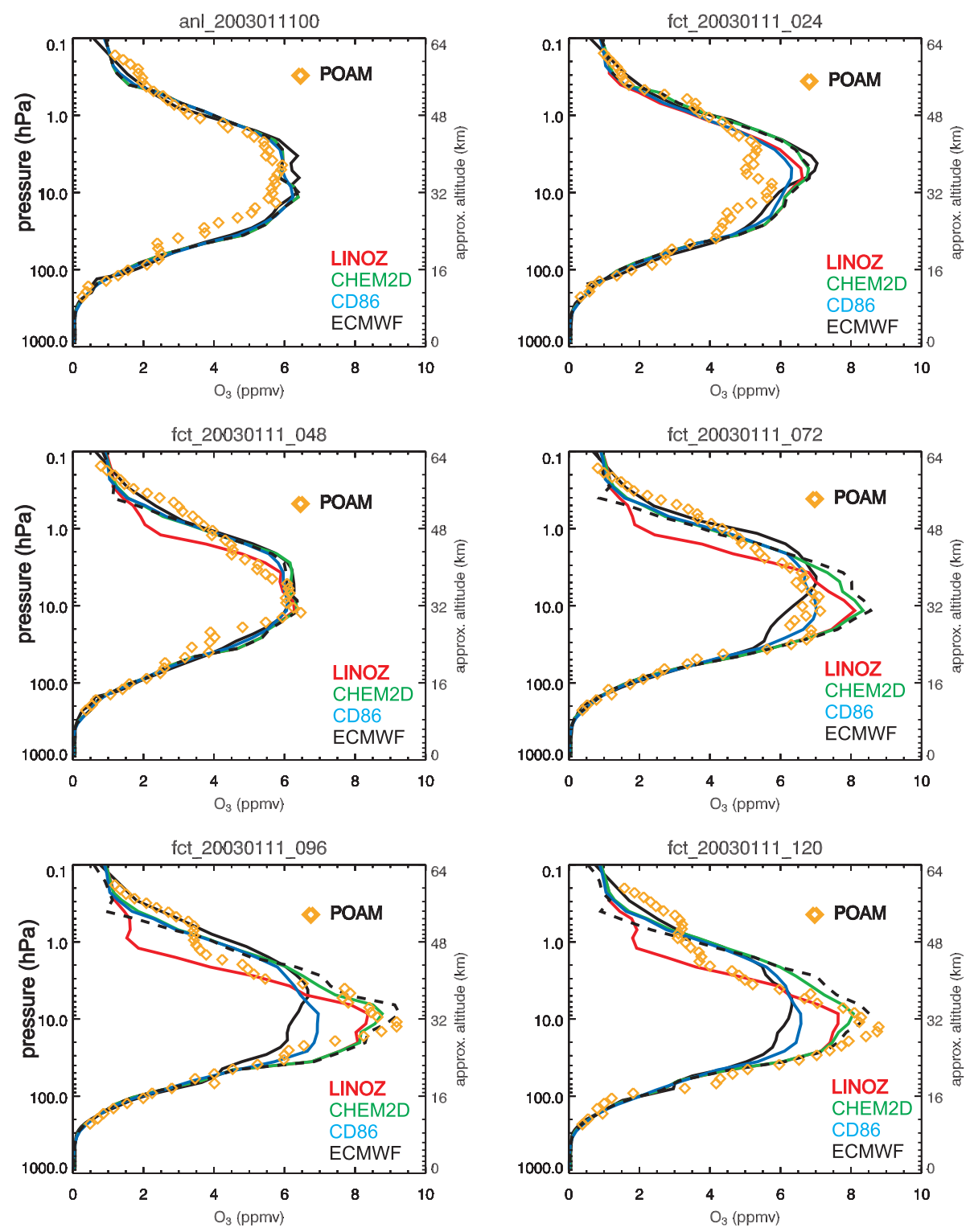

Fig. 11. As in Fig. 10, but now comparing NOGAPS-ALPHA ozone mixing ratio profiles at $65^{\circ} \mathrm{N}, 135^{\circ} \mathrm{E}$ with nearby POAM III ozone profiles (orange symbols).

( $>475 \mathrm{DU}$ ) over Siberia $\left(65^{\circ} \mathrm{N}, 135^{\circ} \mathrm{E}\right)$, and the "arm" of 370-420 DU values extending eastward from the Mediterranean that are all present in the EPTOMS observations in Fig. 8.

Figure $12 \mathrm{~b}$ plots the corresponding $96-\mathrm{h}$ operational ECMWF forecast total ozone distribution initialized on 11 January 2003 and valid for $0 \mathrm{Z} 14$ January 2003. In comparison with the NOGAPS-ALPHA and EPTOMS total ozone fields, the ECMWF total ozone forecast for this time exhibits much smoother zonal structure in the total ozone at middle and high latitudes. Furthermore, the ECMWF total ozone values for this date fail to fully capture the observed area of total ozone values below 235 DU over the North Atlantic sector.

Figure 12c plots NOGAPS-ALPHA total ozone at hour 96 from a run using the CD86 photochemistry scheme and NASA GEOS4 ozone analyses for initialization. We find that the NOGAPS-ALPHA T239 run using the CD86 scheme and the GEOS4 initialization still captures the observed minimum in total ozone over the North Atlantic sector, but overall the zonal variations in the total ozone around $60^{\circ} \mathrm{N}$ are noticeably smaller than in either the EPTOMS total ozone (Fig. 8) or the comparable NOGAPS-ALPHA T239 simulation using the CHEM2D photochemistry (Fig. 12a). It 
(a)
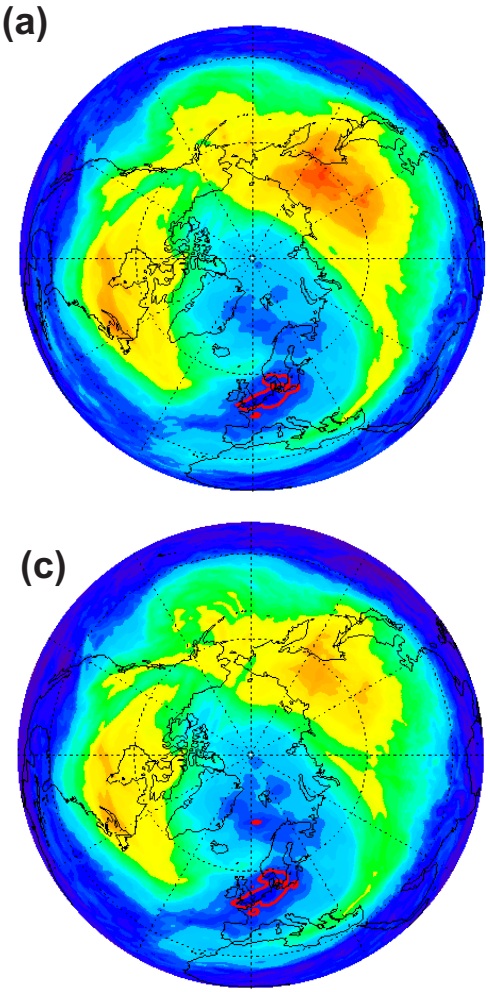

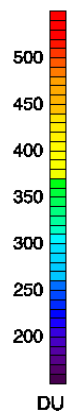

(b)

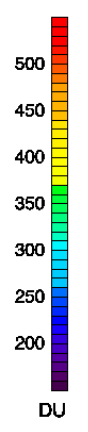

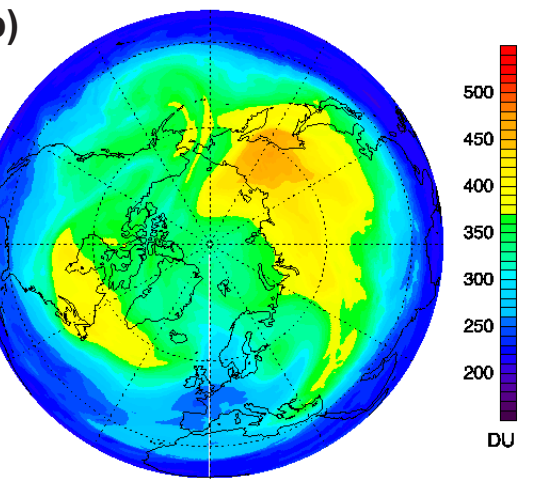
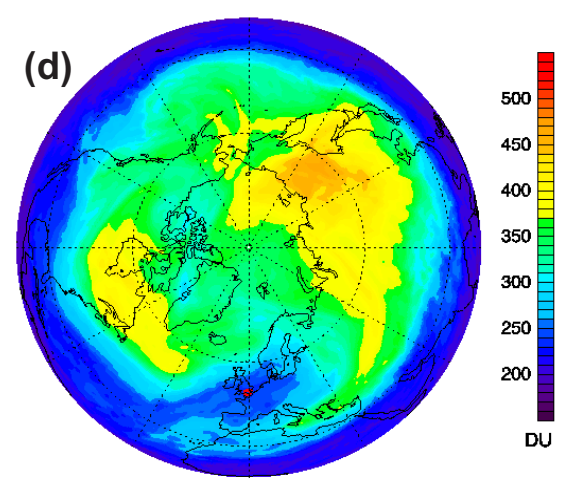

Fig. 12. (a) T239L54 NOGAPS-ALPHA total ozone at hour 96 of 5-day simulation initialized 0 Z 11 January 2003 (valid 0 Z 15 January) with NASA GEOS4 ozone analyses and using the CHEM2D photochemistry scheme; (b) total ozone from corresponding 96-h operational T511L60 96-h ECMWF IFS ozone forecast; (c) same as in (a) but using the CD86 photochemistry scheme and initialized with the NASA GEOS4 ozone analyses; (d) same as in (a) but using the CD86 photochemistry scheme and ECMWF ozone initialization. Red contours enclose regions of total ozone $<235 \mathrm{DU}$.

is important to note that the only difference between the NOGAPS-ALPHA results plotted in Fig. 12a and 12c is the photochemistry scheme, indicating that differences in the details of the photochemistry parameterization are affecting the total ozone distribution at high winter latitudes.

Figure $12 \mathrm{~d}$ plots the resulting NOGAPS-ALPHA 96-h total ozone forecast using the CD86 scheme and ECMWF ozone initialization. This configuration is chosen to match the ozone photochemistry and initialization used in the operational ECMWF IFS forecasts. The total ozone distribution in Fig. 12d bears a very close resemblance to the operational 96-h ECMWF total ozone forecast shown in Fig. 12b. Since similar photochemistry and initialization procedures are employed, the only major factor leading to differences in the NOGAPS-ALPHA total ozone in Fig. 12d and ECMWF total ozone in Fig. 12b should be related to transport. The good agreement between Fig. 12b and 12d indicates that spectral transport in this 96-hour T239 NOGAPS-ALPHA hindcast compares quite well with the operational ECMWF model in the lower stratosphere for this case.

Taken together, the results in Fig. 12 demonstrate that the differences between the CD86 and CHEM2D photochem- istry schemes can significantly impact prognostic $\mathrm{O}_{3}$ in the lower stratosphere over the course of several days. Specifically, the CD86 scheme tends to relax lower stratospheric ozone back to a zonal mean basic state more quickly than the CHEM2D scheme, producing total ozone fields with less zonal structure than observations indicate.

Based on these results, we find that the major differences between operational ECMWF ozone forecasts and NOGAPS-ALPHA ozone simulations for the 11-16 January case are due to (1) ECMWF ozone analyses not capturing the observed ozone minimum over the North Atlantic sector in the model initial conditions for 11 January 2003 (see Fig. 9); and (2) shorter stratospheric ozone photochemical relaxation times $\tau_{\mathrm{O}_{3}}$ in the CD86 scheme as compared to either the CHEM2D or LINOZ schemes. The intercomparison of different $\mathrm{O}_{3}$ photochemistry parameterizations in NOGAPSALPHA for this case shows that the CHEM2D photochemistry parameterization produced the best overall agreement with satellite-based ozone profile measurements and total ozone column abundances. 

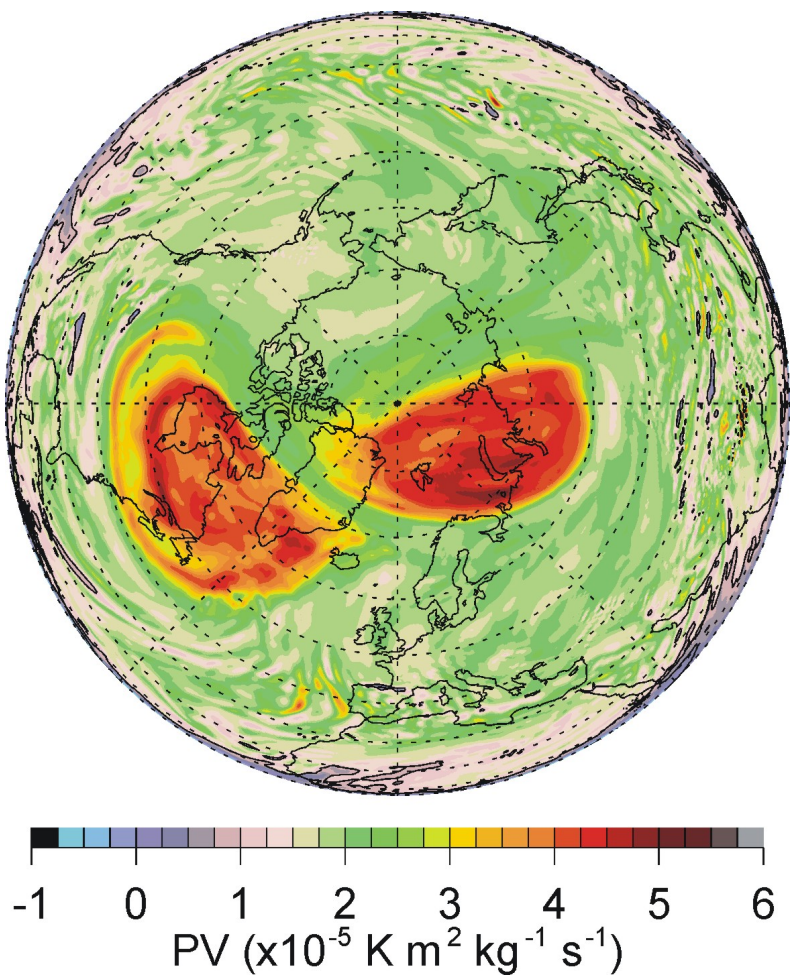

Fig. 13. Ertel's potential vorticity (EPV) on the $460 \mathrm{~K}$ isentropic surface computed from ECMWF T511L60 operational analysis on 21 January 2003 at $18 \mathrm{Z}$.

\section{Case 2: 17-22 January 2003}

\subsection{Description}

Case 2 corresponds to the early period of the stratospheric warming that characterized the SOLVE2 winter (Fig. 1).

Figure 13 plots values of Ertel's potential vorticity on the $460 \mathrm{~K}$ isentropic surface computed from the operational T511L60 ECMWF meteorological analysis issued for $18 \mathrm{Z}$ on 21 January 2003. As Fig. 13 shows, the polar vortex had split into two lobes by 21 January. This disturbed stratospheric meteorology during 17-22 January presents an excellent test for the NOGAPS-ALPHA GCM generally, and its internal spectral chemical advection scheme specifically. An earlier study of prognostic skill in the lower stratosphere by Lahoz (1999) using various high-altitude versions of the United Kingdom Meteorological Office (UKMO) Unified Model focused on hindcasting during February 1994. This period yielded a minor wave- 2 warming with a split vortex structure very similar morphologically to that seen in Fig. 13 (see, e.g. Lahoz's Fig. 7a and Fig. 7b).

Lahoz (1999) noted that the UKMO models' NWP skill tended to be poorest during this period of rapidly evolving mean flow, and cited these cases as requiring careful scrutiny when operational forecasts were used to plan aircraft flights for Arctic science missions. In light of this previous work,

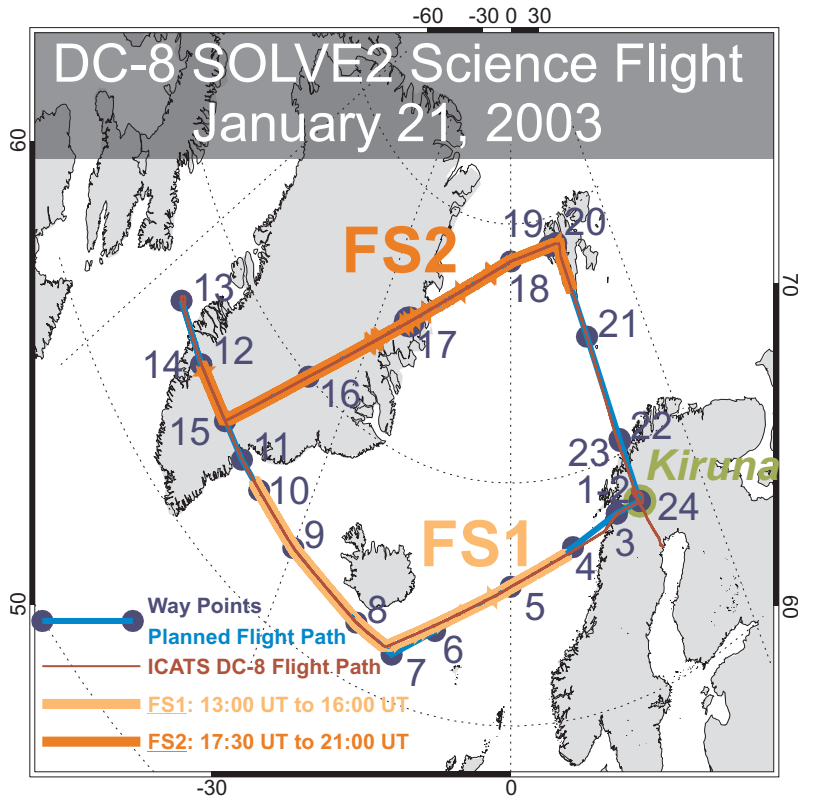

Fig. 14. Flight track of NASA DC-8 SOLVE2 science flight on 21 January 2003. Light blue curve shows planned flight track, with planned way points numbered with dark blue circles. Actual flight track, from the on-board Information Collection and Transmission System (ICATS), is plotted in dark red. This DC-8 flight ended in Lulea, southeast of Kiruna, due to icy runway conditions at Kiruna. Two flight segments chosen for further analysis are shown in light orange and light red, corresponding to flight times shown in the bottom-left of the plot.

the 17-21 January period presents a highly relevant case for studying model performance within the context of airborne SOLVE2 science flights. The rapid dynamical evolution of this case provides a rigorous test case for our new spectral advection formulation for transporting ozone. For this case, we will study prognostic ozone in the lower stratosphere only (below $\sim 10 \mathrm{hPa}$ ), where photochemical lifetimes at all latitudes are long compared to forecasting timescales (Fig. 6). This serves as a test of the model's advection code using ozone as our diagnostic variable.

\subsection{Lidar ozone profiles from SOLVE2 DC-8 flight}

To validate NOGAPS-ALPHA's prognostic ozone during Case 2, we utilize DC-8 data acquired during a science flight on 21 January 2003 (see Fig. 14). For comparison, we have chosen two flight segments for detailed analysis. The first flight segment, denoted FS-1, is shown in light-orange in Fig. 14. From Fig. 13, we see that first part of FS-1 heads away from the split polar vortices as the aircraft flies south of Iceland from Kiruna. The second part of FS-1 then heads back into the split polar vortices as the DC- 8 proceeds north toward Greenland. The second flight segment (FS-2) involves an approximately linear transect from southern Greenland to Svalbard, flying across the split vortex lobe structures 


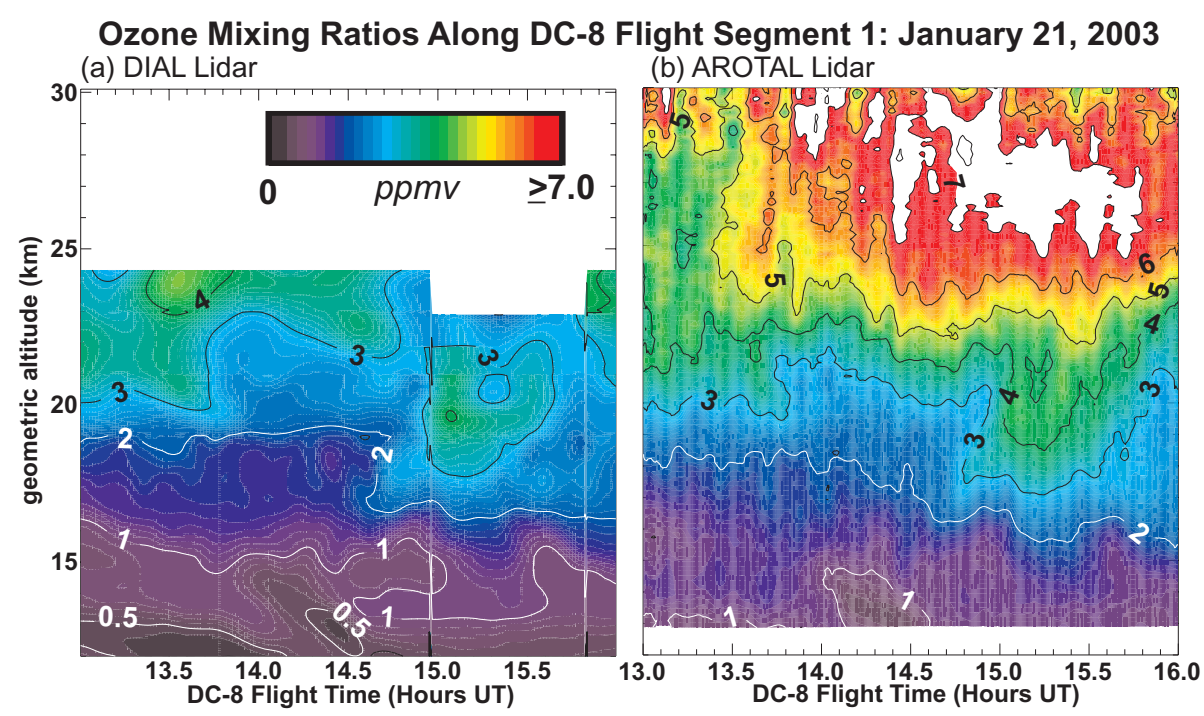

Fig. 15. Ozone mixing ratios (ppmv) as a function of geometric altitude along DC- 8 flight segment 1 (FS-1) as measured by (a) DIAL lidar and (b) AROTAL lidar on 21 January 2003. The AROTAL values were smoothed along the time axis using a 9-point running average to reduce noisiness at upper levels caused by acquisition of data in sunlight. Color scale is 0-7 ppmv: values $>7$ ppmv are shaded white for AROTAL. White regions for DIAL denote missing data.

Ozone Mixing Ratios Along DC-8 Flight Segment 2: January 21, 2003
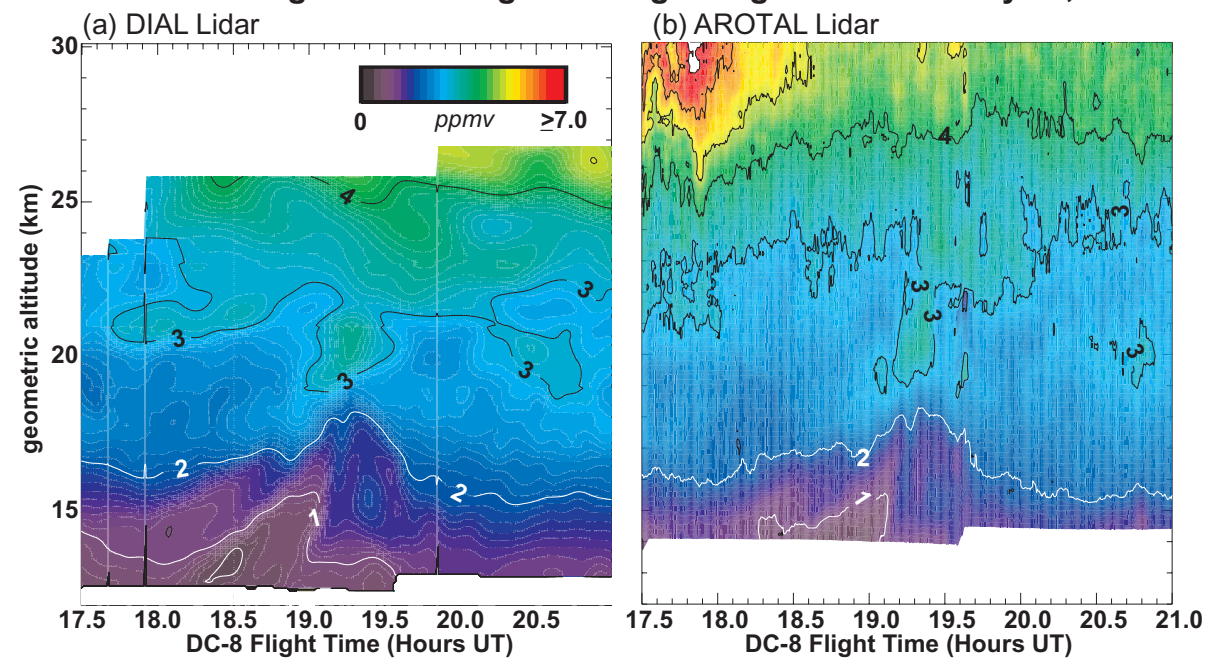

Fig. 16. Ozone mixing ratios (ppmv) as a function of geometric altitude along DC-8 flight segment 2 (FS-2) as measured by (a) DIAL lidar and (b) AROTAL lidar on 21 January 2003. AROTAL values were not smoothed here due to greater signal-to-noise provided by data acquisition in polar night. Color scale is $0-7$ ppmv: values $>7 \mathrm{ppmv}$ are shaded white for AROTAL. White regions for DIAL denote missing data.

shown in Fig. 13. FS-2 potentially profiles mid-latitude lowPV air from a filament separating the two lobes at the approximate midpoint of this flight segment.

Figures 15 and 16 plot ozone mixing ratios acquired along FS-1 and FS-2, respectively, from the DIAL and AROTAL lidar systems on board the DC-8. Both lidar systems reproduce the same major features. For FS-1, the lidar data in Fig. 15 show ozone mixing ratios near $20 \mathrm{~km}$ decreasing slightly as the DC-8 heads southwest to Iceland, then increasing substantially through the stratosphere during part of its north- ward trek toward the coast of Greenland. For FS-2, mixing ratios are generally smaller, with AROTAL upper-level mixing ratios decreasing with time along the flight segment. Near the midpoint of FS-2, both lidars show a sloping upward bulge of low ozone air at $\sim 15 \mathrm{~km}$ and a narrow increase in ozone mixing ratio at $\sim 19: 20 \mathrm{Z}$ at heights $\sim 15-20 \mathrm{~km}$ and, in AROTAL, again at $\sim 30 \mathrm{~km}$. This seems to be a possible ozone signature of the filament of low-PV air separating the split vortex lobes, noted in Fig. 13. 


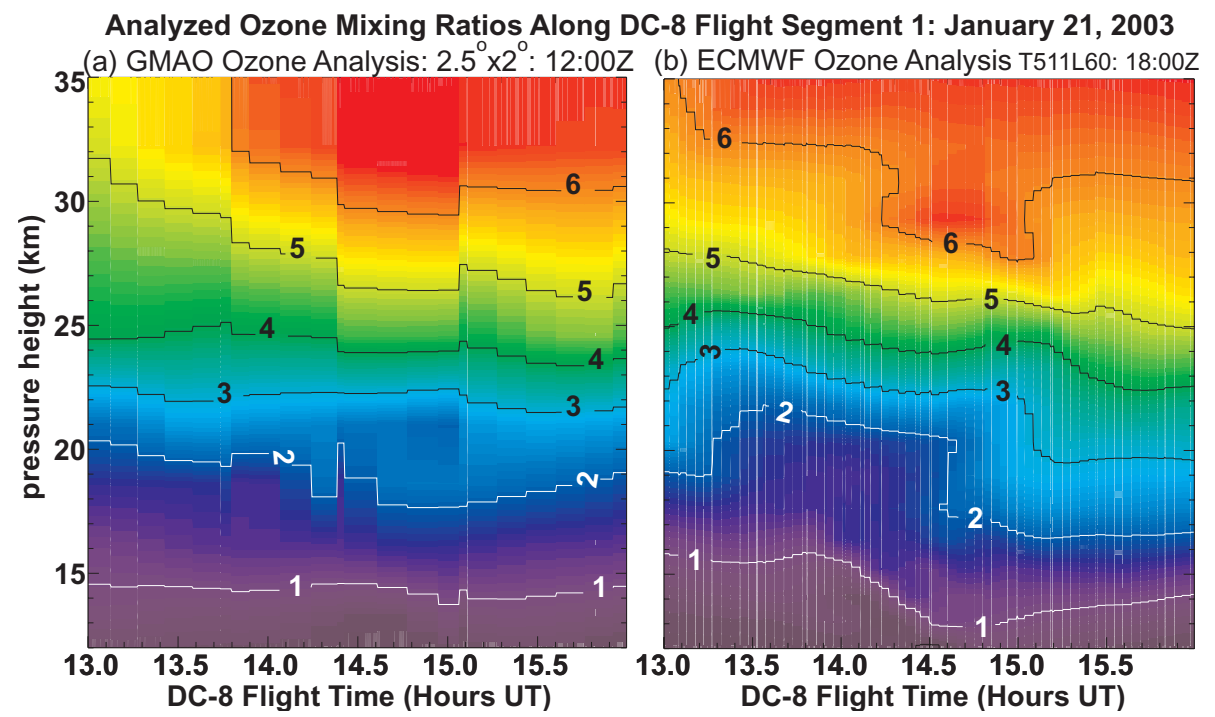

Fig. 17. Analysis ozone mixing ratios (ppmv) as a function of pressure altitude along the DC-8 flight segment 1 (FS-1) from (a) GEOS4 $2.5^{\circ} \times 2^{\circ}$ analysis, and (b) operational ECMWF analysis fields from T511L60 model (on a reduced N256 grid). Both analyses are for 21 January 2003: GEOS4 is taken at $12 \mathrm{Z}, \mathrm{ECMWF}$ is taken at $18 \mathrm{Z}$. Altitude range is extended to $\sim 35 \mathrm{~km}$ to account for differences in pressure and geometric altitudes (see Fig. 19).

Analyzed Ozone Mixing Ratios Along DC-8 Flight Segment 2: January 21, 2003
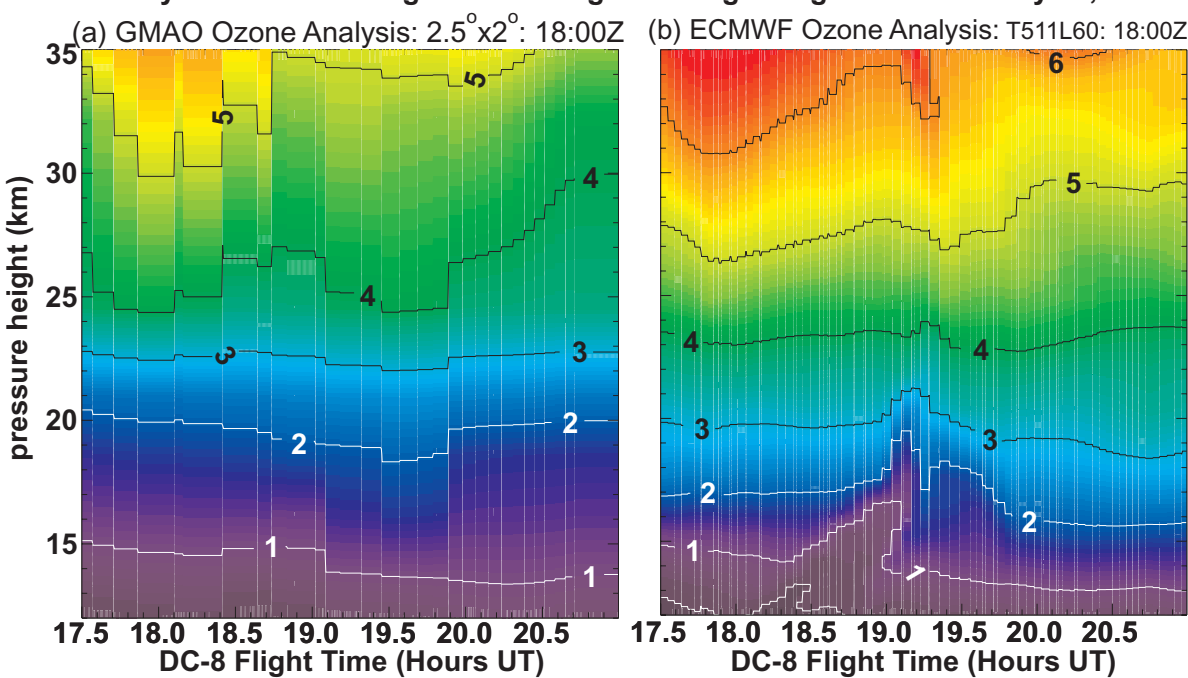

Fig. 18. Analysis ozone mixing ratios (ppmv) as a function of pressure altitude along the DC-8 flight segment 2 (FS-2) from (a) GEOS4 $2.5^{\circ} \times 2^{\circ}$ analysis, and (b) operational ECMWF analysis fields from T511L60 model (on a reduced N256 grid). Both analyses here are for 21 January 2003 at $18 \mathrm{Z}$. Altitude range is extended to $\sim 35 \mathrm{~km}$ to account for differences in pressure and geometric altitudes (see Fig. 19).

\subsection{Comparison with ozone analyses}

We begin by comparing the ECMWF and GEOS4 ozone analyses along the DC-8 flight track to determine if either system captures any of the features seen in the DC-8 lidar data. Fig. 17 plots ozone mixing ratios for 21 January 2003 from the GEOS4 analysis (at 12 Z) and the operational ECMWF analysis (at $18 \mathrm{Z}$ ), these two times roughly spanning the $13-16 \mathrm{Z}$ period of FS-1. Note the much coarser spatial resolution of the GEOS4 ozone analysis that provides initial conditions for prognostic ozone in NOGAPS-ALPHA. Both analyses capture the downward sloping ozone isopleths at $\sim 20-30 \mathrm{~km}$. The ECMWF analysis also captures the reduction in ozone at $\sim 20 \mathrm{~km}$ from $\sim 13: 30-14: 30 \mathrm{Z}$ and the sudden increase at $\sim 14: 30 \mathrm{Z}$.

Figure 18 plots ozone analyses along FS-2, using $18 \mathrm{Z}$ fields for both analyses in this case. Both analyses capture large ozone mixing ratios at upper levels at the start 
NOGAPS-ALPHA T239L54 Ozone Along Flight Segment 2: Initialized 2003011700, +114 Hour Forecast

(a) Ozone Versus Pressure Height

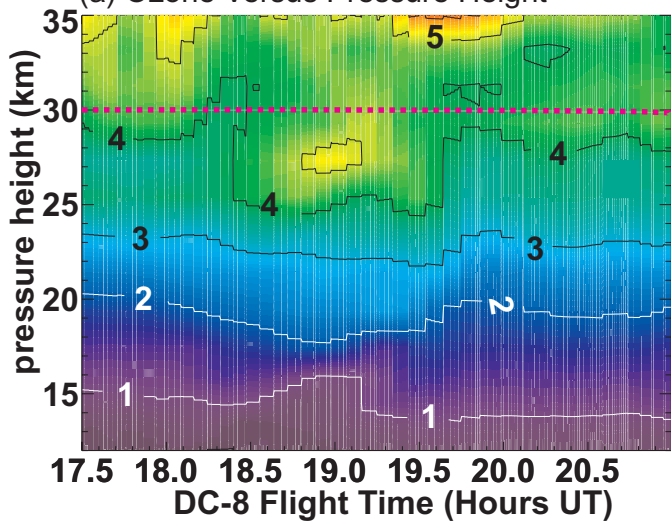

(b) Ozone Versus Geopotential Height

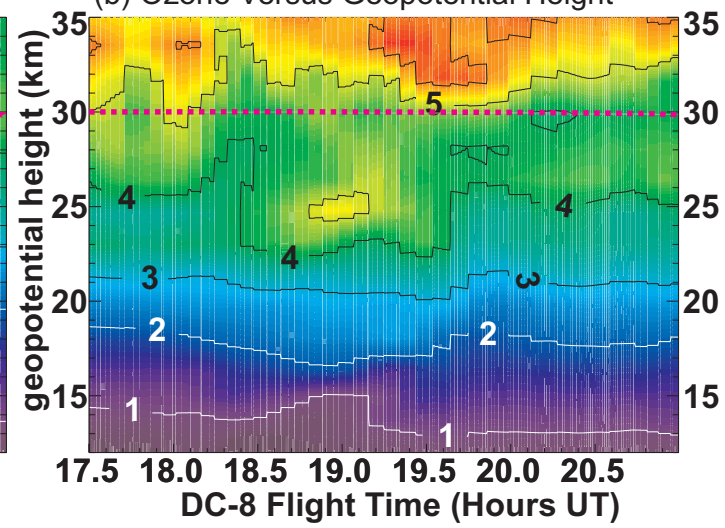

Fig. 19. NOGAPS-ALPHA T239L54 +114h hindcast $\mathrm{O}_{3}$ (ppmv) for 21 January 2003 at $18 \mathrm{Z}$, plotted along DC-8 flight segment 2 as a function of (a) pressure height, and (b) geopotential height. The latter is more directly comparable to the geometric heights used for the lidar ozone profiles in Fig. 16; dotted pink line shows $30 \mathrm{~km}$ upper boundary of lidar plot.

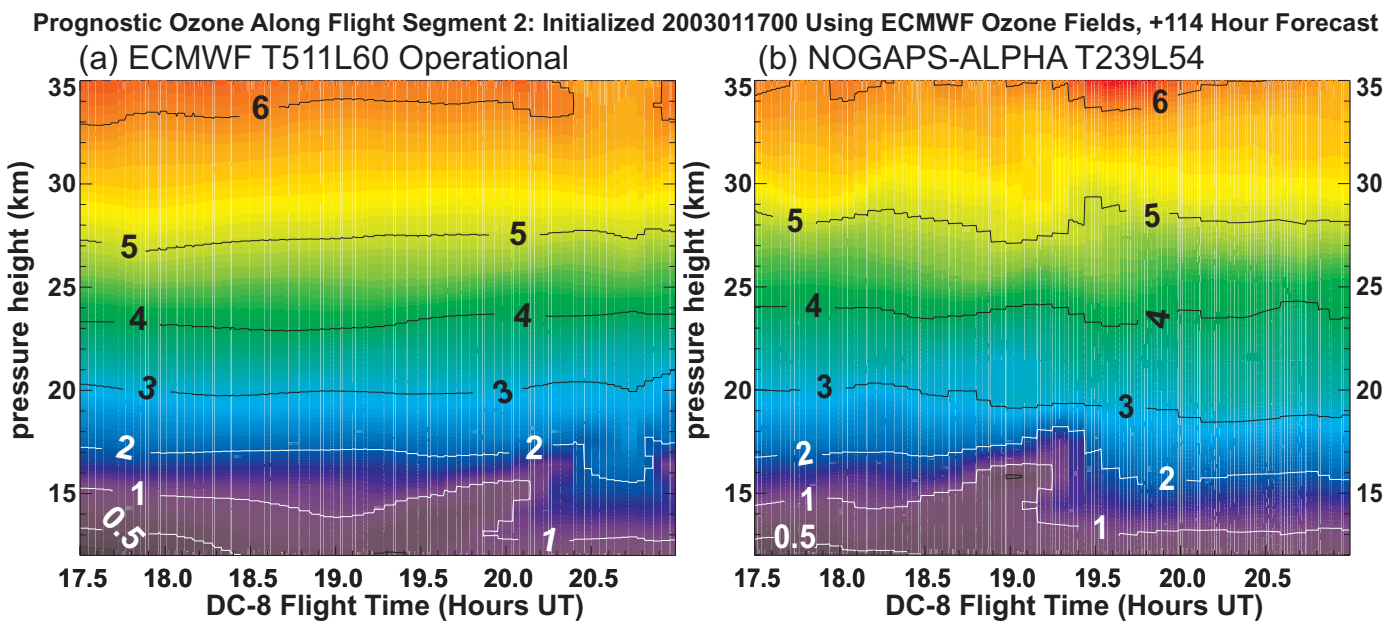

Fig. 20. (a) Archived ECMWF IFS T511L60 114-h operational forecast $\mathrm{O}_{3}$ mixing ratio (ppmv) valid for 21 January 2003 at $18 \mathrm{Z}$, plotted along DC-8 flight segment 2 as a function of pressure height; (b) corresponding 114-hour T239L54 NOGAPS-ALPHA O 3 hindcast initialized with ECMWF analyzed ozone.

of the flight segment, and progressive reductions in these mixing ratios along the flight track. Near the midpoint of the flight, the higher-resolution ECMWF ozone analysis also shows what appears to be an ozone signature of the PV filament separating the two vortex lobes. At $\sim 15 \mathrm{~km}$ and $\sim 30$ $35 \mathrm{~km}$, the structure is similar to that seen in the lidar data in Fig. 16. At $\sim 20 \mathrm{~km}$, however, the lidar data show an ozone enhancement at 19:00-19:30 Z, whereas the analyzed ECMWF ozone shows a slight depletion.

\subsection{NOGAPS-ALPHA O 3 hindcasts: 17-22 January 2003}

Since NOGAPS-ALPHA is usually initialized with the coarse resolution GEOS4 ozone product shown in Figs. 17a and $18 \mathrm{a}$, it is not clear whether the higher-resolution
(T239L54) NOGAPS-ALPHA model dynamics can reproduce observed finer-scale features in the DC- 8 lidar ozone profiles. This section compares T239L54 NOGAPS-ALPHA prognostic ozone fields along the selected DC-8 flight tracks on 21 January initialized with either the lower-resolution GEOS4 analyses or the higher-resolution ECMWF analyses to illustrate the impact of model initial conditions on prognostic $\mathrm{O}_{3}$.

Figure 19 plots T239L54 NOGAPS-ALPHA prognostic ozone fields along FS-2 for the 114-h forecast initialized using GEOS4 analyzed ozone on 17 January at $0 \mathrm{Z}$ (valid on 21 January 2003 at $18 \mathrm{Z}$, the approximate time of FS-2). This simulation uses the CHEM2D photochemistry scheme. The two panels plot the same data, first as a function of pressure altitude, then as a function of geopotential altitude. 
Prognostic Ozone Along Flight Segment 2: Initialized 2003012000, +42 Hour Forecast
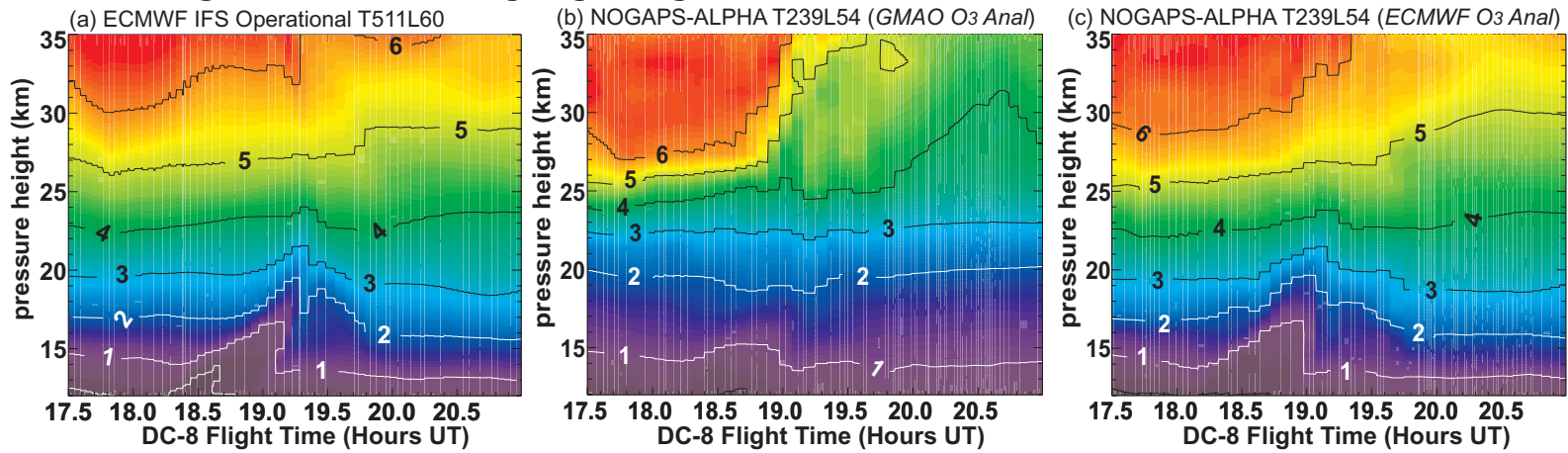

Fig. 21. (a) Archived ECMWF IFS T511L60 42-h operational forecast $\mathrm{O}_{3}$ mixing ratio (ppmv) for 21 January 2003 at $18 \mathrm{Z}$, plotted along DC-8 flight segment 2 as a function of pressure height; (b) NOGAPS-ALPHA T239L54 42-h hindcast $\mathrm{O}_{3}$ along flight segment 2, initialized with GEOS4 analyzed ozone; (c) same as in (b) but initialized with operational ECMWF analyzed $\mathrm{O}_{3}$.

At these altitudes NOGAPS-ALPHA model levels coincide with isobaric surfaces (see Fig. 2), and pressure altitude is computed directly from these values assuming a scale height of $7 \mathrm{~km}$. Geopotential heights, on the other hand, are more directly comparable to the geometric altitudes at which the lidar ozone data are registered in Fig. 16. Figure 19 shows that lower stratospheric pressure altitudes are typically $\sim 2$ $4 \mathrm{~km}$ higher than the corresponding geopotential height altitudes. This vertical offset between lidar geometric altitudes and model pressure altitudes should be borne in mind during the subsequent along-track ozone comparisons.

Despite initialization with the lower-resolution GEOS4 ozone analysis, the NOGAPS-ALPHA 114-h hindcast of ozone mixing ratios along FS-2 in Fig. 19b shows interesting similarities to the DC-8 lidar data in Fig. 16. In particular, the forecast reproduces the sloping low-ozone bulge at $\sim 14 \mathrm{~km}$ at $\sim 18: 30-19: 00 \mathrm{Z}$, and also produces an isolated ozone enhancement in the lower stratosphere, starting at $\sim 19-20 \mathrm{~km}$ and extending upwards, similar to what is seen in the lidar data in Fig. 16. These features arise in the NOGAPSALPHA forecast when the vortex splits and a thin filament of mid-latitude air is drawn polewards, separating the two vortex lobes. However, the width of this NOGAPS-ALPHA ozone enhancement is broader in this 114-h hindcast than the actual ozone filament width seen in the lidar profiles.

Figure 20a plots the corresponding archived T511L60 ECMWF 114-h ozone forecast for 21 January 2003 at $18 \mathrm{Z}$. This forecast yields an ozone filament, but its location along the flight track is incorrect by $30-60 \mathrm{~min}$; the sloping lowozone enhancement occurs at $\sim 19: 30-20: 00 \mathrm{Z}$ and the stratospheric ozone anomalies due to the filament occur towards the end of the flight segment at $\sim 20: 40 \mathrm{Z}$. The location of this ozone anomaly along the flight track significantly improves with the +90-h ECMWF forecast (not shown).

The ECMWF IFS +114-h ozone forecasts in Fig. 20a are also somewhat featureless above $20 \mathrm{~km}$, lacking much of the structure noted in the corresponding NOGAPS-ALPHA
GEOS4-initialized ozone hindcast in Fig. 19. To assess the role of the different initial ozone fields that were used, we repeated the NOGAPS-ALPHA hindcast from Fig. 19, but this time replaced the +0-h GEOS4 ozone analysis with the +0 -h ECMWF IFS ozone analysis. The resulting ECMWFinitialized +114-h NOGAPS-ALPHA prognostic ozone field in Fig. 20b shows no evidence of the filament and related structure above $20 \mathrm{~km}$ noted in the corresponding GEOS4-based ozone run in Fig. 19a. The similarity between Figs. 20a and 20b indicates that the lack of structure above $\sim 20 \mathrm{~km}$ in the ECMWF ozone forecast is due, at least in part, to the ECMWF ozone initialization, which, as we demonstrated in Sect. 4, underpredicts the geographical variability at high latitudes. An additional contribution to the reduced spatial variability in Fig. 20a may also result from the shorter relaxation time $\tau_{\mathrm{O} 3}$ in the CD86-based ECMWF photochemistry scheme compared to the NRL-CHEM2D scheme, previously noted in section 4 .

Another difference between the ECMWF IFS forecasts and NOGAPS-ALPHA simulations for this date is that, in the lower stratosphere, the ECMWF ozone forecasts improve with each forecast update more noticeably than do the NOGAPS-ALPHA hindcasts based on GEOS4 ozone. For example, Fig. 21a plots the 42-h ozone forecast along FS-2 from the T511L60 ECMWF IFS, while Fig. 21b plots the NOGAPS-ALPHA hindcast initialized with GEOS4 $\mathrm{O}_{3}$ fields on 20 January at $0 \mathrm{Z}$. The lower stratospheric filament fields are much less well resolved in the NOGAPS-ALPHA forecast in Fig. 21b.

One possible explanation for this difference is resolution. The ECMWF IFS employs a high horizontal resolution analysis field whereas the NOGAPS-ALPHA simulation used the NASA GEOS4 ozone analyses, at the much coarser $2.5^{\circ} \times 2^{\circ}$ horizontal resolution, for initialization (Fig. 18). Longer forecasts are less influenced by model initial conditions and more influenced by model physics. For shorter forecasts, the opposite is true. It is possible that the lower horizontal res- 


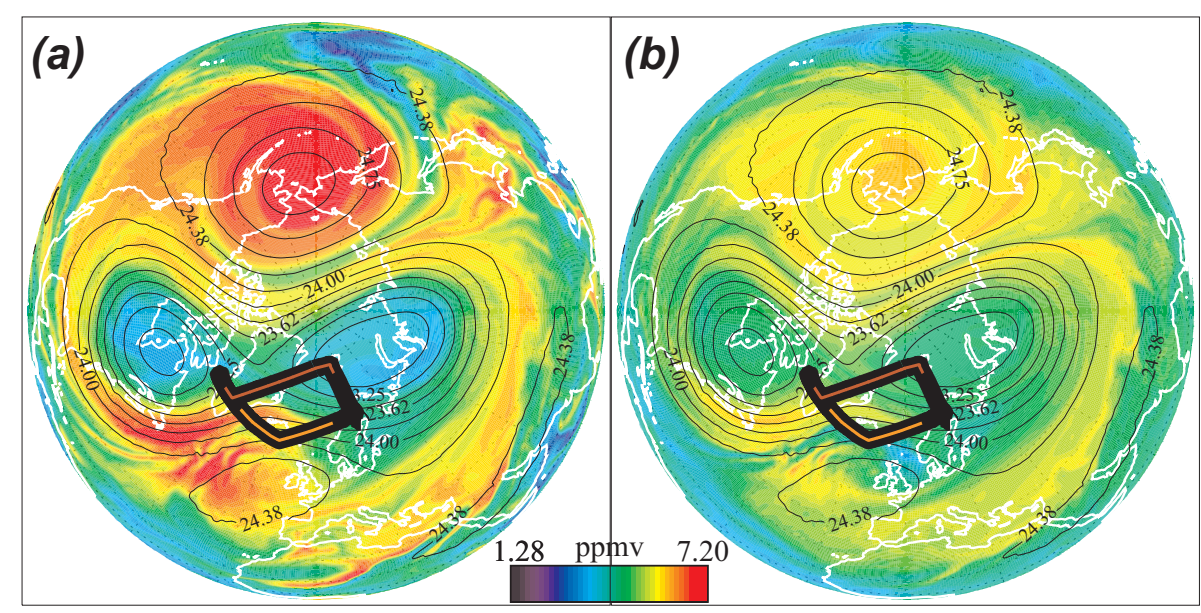

Fig. 22. (a) NOGAPS-ALPHA T239L54 42-h hindcast of $\mathrm{O}_{3}$ mixing ratios (ppmv) at $26.7 \mathrm{hPa}$, valid for 21 January 2003 at $18 \mathrm{Z}$, initialized with GEOS4 analyzed $\mathrm{O}_{3}$; (b) same as in (a) but initialized with ECMWF analyzed $\mathrm{O}_{3}$. The DC-8 flight and flight segments (FS-1, FS-2) from Fig. 14 are overplotted. Contours are geopotential heights in kilometers.

olution of the GEOS4 ozone initialization imposes a greater limitation on the subsequent NOGAPS-ALPHA ozone forecast as these forecasts are initialized progressively closer to the actual flight time and thus are run for a shorter time.

To explore this possibility, we repeated the same $+42-\mathrm{h}$ NOGAPS-ALPHA forecast that produced Fig. 21b, but instead used as our +0-h ozone field the ECMWF IFS analysis instead of the GEOS4 analysis. The result is plotted in Fig. 21c, and reveals mid-flight isopleth filament structure in the lower stratosphere that much more closely resembles the ECMWF IFS 42-h ozone forecast in Fig. 21a. The similarity suggests that NOGAPS-ALPHA prognostic meteorological transport is similar to ECMWF's in this case, and thus that the differences between Figs. 21a and 21b are due mostly to differences in the initial ozone fields. The differences between Figs. 21b and 21c confirm that, for shorter forecast times, the coarser resolution of the GEOS4 ozone initialization imposes a limit on quality of the ozone forecast.

Finally, we examine the hemispheric impact of different initial ozone fields on NOGAPS-ALPHA prognostic $\mathrm{O}_{3}$. Figure 22a plots a synoptic map of the T239L54 NOGAPSALPHA 42-h ozone hindcast at $26.7 \mathrm{hPa}$ on 21 January 2003 at $18 \mathrm{Z}$ initialized with GEOS4 analyzed ozone fields. The DC-8 flight track for this date is included for reference. This map shows a tongue of high ozone air near southern Greenland that has wrapped around the western vortex lobe and intercepts FS-1 near the end of this flight segment. This accounts for the increase in stratospheric ozone mixing ratios observed in the FS-1 lidar data at $\sim 15 \mathrm{Z}$ (Fig. 15) near the end of this flight segment. Figure 22a also shows low ozone mixing ratios in the cores of the two vortex lobes and higher ozone between the vortex lobes, roughly traversed by FS-2.

Figure 22b plots the corresponding synoptic map of T239L54 NOGAPS-ALPHA 42-h ozone hindcast initialized instead with ECMWF analyzed ozone. The range of ozone values here is much reduced compared to Fig. 22a, which is consistent with earlier findings for ECMWF analysis and total ozone maps in section 4 (see Figs. 9 and 12). However, inspection of plot pairs like Fig. 22 for all the NOGAPSALPHA stratospheric model levels (not shown) revealed a systematic height-dependence to these comparisons. The lack of structure and variability in ECMWF-initialized ozone hindcasts only occurs noticeably at altitudes above $\sim 50 \mathrm{hPa}$. At pressures $\sim 120-50 \mathrm{hPa}$, NOGAPS-ALPHA ozone hindcasts initialized with ECMWF ozone analysis actually show as much, or even slightly more ozone structure and variability than the corresponding GMAO-initialized ozone hindcast, and, as noted by comparing Figs. 16, 20b, and 21c, the comparison with observations at these altitudes is quite good. This suggests that the exclusion of satellite data from the ECMWF ozone assimilation poleward of $40^{\circ}$ has serious consequences only at altitudes above $\sim 50 \mathrm{hPa}$ : below that, ECMWF assimilated ozone fields are more realistic.

\section{Summary and conclusions}

We have tested the new prognostic ozone component of the NOGAPS-ALPHA middle atmosphere forecast model for two distinct cases during the 2003 SOLVE II campaign: (1) 11-16 January 2003, when the polar vortex was relatively cold and stable; and (2) 17-22 January 2003, when a rapidly developing stratospheric warming split the vortex into two separate lobes. Initial comparisons of NOGAPS-ALPHA 5-day stratospheric ozone hindcasts with a combination of satellite and aircraft measurements of polar ozone indicate that the performance of the new prognostic ozone for these two cases is comparable to current operational ECMWF 
ozone forecasts. Specific results for the individual cases are summarized below.

For the case of 11-16 January 2003 (Case 1), an intercomparison of three different linearized ozone gas-phase photochemistry schemes found that all three schemes generated forecast ozone profiles in good agreement with the SAGE III and POAM III solar occultation measurements at high latitudes at and below $10 \mathrm{hPa}$. Above $10 \mathrm{hPa}$, NOGAPSALPHA ozone simulations using the LINOZ scheme of McLinden et al. (2000) generated excessive ozone losses over the course of the 5-day forecast in disagreement with observations. These losses are evident at all latitudes above $10 \mathrm{hPa}$, and suggest that the LINOZ scheme may not be suitable for upper stratosphere applications. At middle latitudes receiving more sunlight, significant differences were found between NOGAPS-ALPHA ozone forecasts using the NRLCHEM2D and CD86 (i.e. Cariolle and Déqué, 1986) ozone photochemistry parameterizations. Specifically, the CD86 scheme produced a smoother zonal structure in lower stratospheric ozone, most likely due to the shorter ozone photochemical relaxation times inherent in the CD86 formulation. A comparison of the NOGAPS-ALPHA prognostic ozone simulations with operational ECMWF ozone forecasts found significant differences due to different model ozone initial conditions. NOGAPS-ALPHA ozone forecasts initialized with the NASA GEOS4 ozone analyses produced much better agreement with satellite measurements at high latitudes than did the operational ECMWF ozone forecasts, particularly in the longitude sector between $10^{\circ} \mathrm{W}-30^{\circ} \mathrm{E}$.

For the case of 17-22 January 2003 (Case 2), NOGAPSALPHA 114-h forecasts of stratospheric ozone along the DC-8 flight track of 21 January produced agreement with DC-8 DIAL and AROTAL ozone profiles which was as good or slightly better than corresponding ECMWF ozone forecasts. Updated (e.g. 42-h) ECMWF ozone forecasts for 21 January rapidly improved their simulation of the split vortex and subsequent fine structure in lower stratospheric ozone mixing ratios; NOGAPS-ALPHA ozone hindcasts initialized with GMAO-GEOS4 analyses did not show such improvement. However, when the higher-resolution ECMWF ozone analyses were used to initialize NOGAPS-ALPHA, the resulting NOGAPS-ALPHA lower stratospheric $\mathrm{O}_{3}$ simulation displayed good agreement with the operational ECMWF 42-hour forecast. The coarser resolution of the GMAOGEOS4 ozone analyses used to initialize NOGAPS-ALPHA prognostic $\mathrm{O}_{3}$ exerts a greater influence on short-term forecasts (i.e. 42-h) than on longer-term (i.e. 114-h) forecasts. Comparisons of NOGAPS-ALPHA and ECMWF prognostic ozone with DC-8 measurements during this period also highlighted the altitude dependence in the quality of the ECMWF ozone analyses and their impact on ozone simulations at high northern latitudes during SOLVE2. Below $50 \mathrm{hPa}$, NOGAPS-ALPHA prognostic ozone initialized with operational ECMWF IFS ozone analyses produced excellent agreement with observations. Above $50 \mathrm{hPa}$, however, ini- tialization with the ECMWF ozone analyses had a detrimental effect on NOGAPS-ALPHA prognostic ozone skill.

Overall, the good agreement between NOGAPS-ALPHA prognostic ozone and both satellite and DC-8 aircraft measurements during the SOLVE2 campaign demonstrate that the model's spectral transport and parameterized photochemistry are capable of providing reliable short-range ozone forecasts. The model-data comparisons highlight the importance of both an accurate parameterized photochemistry scheme and an accurate global operational ozone assimilation for prognostic ozone during the SOLVE2 Arctic winter case studies. More detailed, quantitative assessments of NOGAPS-ALPHA prognostic $\mathrm{O}_{3}$ skill in the troposphere and stratosphere are currently underway. Future work will include development of the temperature and column ozone terms in the NRL-CHEM2D linearized gas-phase photochemistry scheme, an additional term to account for heterogeneous chemical losses associated with polar stratospheric clouds, and improvements in the ozone initialization. The ultimate goal of this work is a fully operational prognostic ozone scheme for the assimilation of satellite radiance measurements.

Acknowledgements. Funding for this work at the Naval Research Laboratory has come in part from the Office of Naval Research, the NASA Office of Earth Science Upper Atmosphere Research Program, and the National Polar Orbiting Environmental Satellite System (NPOESS) Integrated Project Office. Thanks to I. Stajner at the NASA Global Modeling and Assimilation Office for providing access and helpful discussions regarding the GEOS4 ozone analyses, to C. McLinden at Environment Canada and H. Teyssedre at Météo France for providing photochemistry parameterization coefficients, and to D. Siskind at NRL for guidance with the CHEM2D model. We also thank two anonymous reviewers for their constructive comments that aided in the interpretation of our results.

Edited by: K. Carslaw

\section{References}

Alexander, M. J. and Dunkerton, T. J.: A spectral parameterization of mean-flow forcing due to breaking gravity waves, J. Atmos. Sci., 56, 4167-4182, 1999.

Austin, J., Shindell, D., Beagley, S. R., Brühl, C., Dameris, M., Manzini, E. M., Nagashima, T., Newman, P., Pawson, S., Pitari, G., Rozanov, E., Schnadt, C. , and Shepherd, T. G.: Uncertainties and assessments of chemistry-climate models of the stratosphere, Atmos. Chem. Phys., 3, 1-27, 2003,

SRef-ID: 1680-7324/acp/2003-3-1.

Baker, N. L.: Quality control for the Navy operational atmospheric database, Wea. Forecasting, 7, 250-261, 1992.

Bevilacqua, R. M., Fromm, M. D., Alfred, J. M., Hornstein, J. S., Nedoluha, G. E., Hoppel, K. W., Lumpe, J. D., Randall, C. E., and Shettle, E. P.: Observations and analysis of PSCs detected by POAM III during the 1999/2000 northern hemisphere winter, J. Geophys. Res., 107(20), 8281, doi:10.1029/2001JD000477, 2002. 
Boville, B. A.: Wave-mean flow interactions in a general circulation model of the troposphere and stratosphere, J. Atmos. Sci., 43, 1711-1725, 1986.

Braesicke, P., Jrrar, A., Hadjinicolaou, P., and Pyle, J.: Variability of total ozone due to the NAO as represented in two different model systems, Met. Z., 12, 203-208, 2003.

Brasseur, G. and Solomon, S.: Middle Atmospheric Chemistry, Aeronomy of the Middle Atmosphere, D. Reidel, Norwell, MA, USA, 2nd ed., 452 pp., 1986.

Burris, J., McGee, T., Hoegy, W., et al.: Validation of temperature measurements from the airborne Raman ozone temperature and aerosol lidar during SOLVE, J. Geophys. Res., 107(D20), doi:10.1029/2001JD001028, 2002.

Butchart, N. and Austin, J.: Middle atmosphere climatologies from the troposphere-stratosphere configuration of the UKMO's unified model, J. Atmos. Sci., 55, 2782-2809, 1998.

Cariolle, D. and Déqué, M.: Southern hemisphere medium-scale waves and total ozone disturbances in a spectral general circulation model, J. Geophys. Res., 91, 10 825-10 846, 1986.

Chou, M.-D. and Suarez, M. J.: A solar radiation parameterization for atmospheric studies, edited by: Suarez, M. J., NASA Tech. Mem. 10460, 15, Technical Report Series on Global Modeling and Data Assimilation, 52, 2002.

Chou, M.-D., Suarez, M. J., Liang, X. Z., and Yan, M.-H.: A thermal infrared radiation parameterization for atmospheric studies, edited by: Suarez, M. J., NASA Tech. Mem. 104606, 19, Technical Report Series on Global Modeling and Data Assimilation, 65, 2001.

Chun, H.-Y. and Baik, J. J.: An updated parameterization of convectively forced gravity wave drag for use in large-scale models, J. Atmos. Sci., 59, 1006-1017, 2002.

Daley, R. and Barker, E.: NAVDAS: formulation and diagnostics, Mon. Wea. Rev., 129, 869-883, 2001.

Derber, J. C. and Wu, W.-S.: The use of TOVS cloud-cleared radiances in the NCEP SSI analysis system, Mon. Wea. Rev., 126, 2287-2299, 1998.

Dethof, A.: Aspects of Modelling and Assimilation for the Stratosphere at ECMWF, SPARC Newsletter 21, http://www.aero. jussieu.fr $/ \sim_{\text {sparc/News21/21_Dethof.html, } 2003 .}$

Dethof, A. and Holm, E.: Ozone in ERA-40: 1991-1996, European Centre for Medium-Range Forecasts Technical Memorandum No. 377, Reading, England, 37, 2002.

Eckermann, S. D., Ma, J., and Broutman, D.: The NRL Mountain Wave Forecast Model (MWFM), Preprint Vol. Symposium on the 50th. Anniversary of Operational Numerical Weather Prediction, American Meteorological Society, University of Maryland, College Park, MD, 14-17 June, Paper P2.9, 20pp, 2004a.

Eckermann, S. D., McCormack, J.P., Coy, L., Allen, D., Hogan, T., and Kim, Y.-J.: NOGAPS-ALPHA: A prototype high-altitude global NWP model, Preprint Vol. Symposium on the 50th Anniversary of Operational Numerical Weather Prediction, American Meteorological Society, University of Maryland, College Park, MD, 14-17 June, Paper P2.6, 23pp, 2004b.

ECMWF: The Description of the ECMWF/WCRP Level III-A Global Atmospheric Data Archive, ECMWF Operations Department, Shinfield Park, Reading, Berkshire, RG3, 9AX, England, 1995.

Emanuel, K. A. and Zivkovic-Rothman, M.: Development and evaluation of a convection scheme for use in climate models, J. At- mos. Sci., 56, 1766-1782, 1999.

Errico, R. M., Barker, E. H., and Gelaro, R.: A determination of balanced normal modes for two models, Mon. Wea. Rev., 116, 2717-2724, 1988.

Fairlie, T. D. A., Turner, R. E., and Siskind, D. E.: Transport characteristics of a finite difference dynamics model combined with a spectral transport model of the middle atmosphere, Mon. Wea. Rev., 122, 2363-2375, 1994.

Fleming, E. L., Chandra, S., Barnett, J. J., and Corney, M.: Zonal mean temperature, pressure, zonal wind, and geopotential height as functions of latitude, COSPAR International Reference Atmosphere: 1986, Part II: Middle Atmosphere Models, Adv. Space Res., 10(12), 11-59, 1990.

Fleming, E., Jackman, C., Considine, D., and Stolarski, R.: Sensitivity of tracers and a stratospheric aircraft perturbation to twodimensional model transport variations, J. Geophys. Res., 106 (D13), 14 245-14 264, doi:10.1029/2000JD900732, 2001.

Fortuin, J. P. F. and Kelder, H.: An ozone climatology based on ozonesonde and satellite measurements, J. Geophys. Res., 103, 31 709-31 734, 1998.

Goerss, J. and Jeffries, R.: Assimilation of synthetic tropical cyclone observations into the Navy Operational Global Atmospheric Prediction System, Wea. Forecasting, 9, 557-576, 1994.

Goerss, J. and Phoebus, P.: The Navy's operational atmospheric analysis, Wea. Forecasting, 7, 232-249, 1992.

Goerss, J., Hogan, T., Sashegyi, K., Holt, T., Rennick, M., Beeck, T., and Steinle, P.: Validation Test Report for the NAVDAS/NOGAPS System, NRL Technical Report, 27, 2003.

Grant, W. B., Browell, E. V., Butler, C. F., Gibson, S. C., Kooi, S. A., and von der Gathen, P.: Estimation of Arctic polar vortex ozone loss during the winter of 1999-2000 using vortexaveraged airborne differential absorption lidar ozone measurements referenced to $\mathrm{N}_{2} \mathrm{O}$ isopleths, J. Geophys. Res, 108 (D10), 4309, doi:10.1029/2002JD002668, 2003.

Harshvardhan, Davies, R., Randall, D., and Corsetti, T.: A fast radiation parameterization for atmospheric circulation models, J. Geophys. Res., 92, 1009-1016, 1987.

Hines, C. O.: Doppler-spread parameterization of gravity-wave momentum deposition in the middle atmosphere, 1 , basic formulation, J. Atmos. Sol.-Terr. Phys., 59, 371-386, 1997.

Hogan, T. and Rosmond, T.: The description of the Navy Operational Global Atmospheric Prediction System's spectral forecast model, Mon. Wea. Rev., 119, 1186-1815, 1991.

Hogan, T. F., Rosmond, T. E., and Gelaro, R.: The NOGAPS forecast model: a technical description, Naval Oceanographic and Atmospheric Research Laboratory Report No. 13, 219, December, 1991.

James, P. M.: A climatology of ozone mini-holes over the Northern hemisphere, Int. J. of Climatol., 18, 1287-1303, 1998.

Jang, K. I., Zou, X., De Pondeca, M. S. F. U., Shapiro, M., Davis, C., and Krueger, A.: Incorporating TOMS ozone measurements into the prediction of the Washington, DC, winter storm during 24-25 January 2000, J. Appl. Meteorol., 42, 797-812, 2003.

Kasahara, A.: Various vertical coordinate systems used for numerical weather prediction, Mon. Wea. Rev., 102, 509-522, 1974 (corrigendum, Mon. Wea. Rev., 103, 664, 1975).

Kim, Y.-J. and Arakawa, A.: Improvement of orographic gravitywave parameterization using a mesoscale gravity-wave model, J. Atmos. Sci., 52, 1875-1902, 1995. 
Lahoz, W. A.: Predictive skill of the UKMO Unified Model in the lower stratosphere, Q. J. R. Meteorol. Soc., 125, 2205-2238, 1999.

Lawrence, B. N.: Some aspects of the sensitivity of stratospheric climate simulation to model lid height, J. Geophys. Res., 102, 23 805-23 811, 1997.

Lin, S.-J. and Williamson, D.: A middle atmosphere extension of the Held-Suarez forcing and age-of-air trace for dynamical core inter-comparison, NASA Global Modeling and Assimilation Office, http://gmao.gsfc.nasa.gov/sci_research/fvdas/ LinWilliamson.ps, 2000.

Louis, J. F.: A parametric model of vertical eddy fluxes in the atmosphere, Boundary Layer Meteorol., 17, 187-202, 1979.

Louis, J. F., Tiedtke, M., and Geleyn, J. F.: A short history of the operational PBL parameterization at ECMWF, ECMWF Workshop on Planetary Boundary Parameterizations, November 1981, 5979, 1982.

McCormack, J. P. and Hood, L. L.: The frequency and size of ozone "mini-hole" events at northern midlatitudes in February, Geophys. Res. Lett., 24, 1997.

McCormack, J. P. and Siskind, D. E.: Simulations of the quasibiennial oscillation and its effect on stratospheric $\mathrm{H}_{2} \mathrm{O}, \mathrm{CH}_{4}$, and age of air with an interactive two-dimensional model, J. Geophys. Res., 107 (D22), 4625, doi:10.1029/2002JD002095, 2002.

McLinden, C. A., Olsen, S. C., Hannegan, B., Wild, O., Prather, M. J., and Sundet, J.: Stratospheric ozone in 3-D models: A simple chemistry and the cross-tropopause flux, J. Geophys. Res., 105, 14 653-14 665, 2000.

McPeters, R. D., Bhartia, P. K., Kreuger, A. J., et al.: Earth Probe Total Ozone Mapping Spectrometer (TOMS) Data Products Users Guide, NASA Technical Publication 1998-206985, 64, NASA Goddard Space Flight Center, Greenbelt, MD, USA, 1998.

Newman, P. A., Lait, L. R., and Schoeberl, M. R.: The morphology and meteorology of southern hemisphere spring total ozone miniholes, Geophys. Res. Lett., 15, 923-926, 1988.

Orsolini, Y., Cariolle, D., and Déqué, M.: Ridge formation in the lower stratosphere and its influence on ozone transport: A general circulation model study during late January 1992, J. Geophys. Res., 100, $11113-11$ 135, 1995.

Palmer, T. N., Shutts, G. J., and Swinbank, R.: Alleviation of a systematic westerly bias in general circulation and numerical weather prediction models through an orographic gravity wave drag parameterization, Q. J. R. Meteorol. Soc., 112, 1001-1039, 1986.

Pawson, S., Langematz, U., Radek, G., Schlese, U., and Strauch, P.: The Berlin troposphere-stratosphere-mesosphere GCM: Sensitivity to physical parameterizations, Q. J. R. Meteorol. Soc., 124, 1343-1371, 1998.

Peng, M. S., Ridout, J. A., and Hogan, T. F.: Recent modifications of the Emanuel convective scheme in the Navy Operational Global Atmospheric Prediction System, Mon Wea. Rev., 132, 1254-1268, 2004.

Pumphrey, H. C., Rind, D., Russell III, J. M., and Harries, J. E.: A preliminary zonal mean climatology of water vapor in the stratosphere and mesosphere, Adv. Space Res., 21, 1417-1420, 1998.

Randel, W. J., Udelhofen, P., Fleming, E., et al.: The SPARC intercomparison of middle-atmosphere climatologies, J. Climate, 17, 986-1003, 2004.
Rasch, P. J. and Williamson, D. L.: Computational aspects of moisture transport in global models of the atmosphere, Q. J. R. Meteorol. Soc., 116, 1071-1090, 1990.

Rood, R. B., Nielsen, E., Stolarski, R. S., Douglass, A. R., Kaye, J. A., and Allen, D. J.: Episodic total ozone minima and associated effects on heterogeneous chemistry and lower stratospheric transport, J. Geophys. Res., 97, 7979-7996, 1992.

Shepherd, T. G., Semeniuk, K., and Koshyk, J. N.: Sponge layer feedbacks in middle-atmosphere models, J. Geophys. Res., 101, 23 447-23 464, 1996.

Simmons, A. J., Hoskins, B. J., and Burridge, D. M.: Stability of semi-implicit time scheme, Mon. Wea. Rev., 106, 405-412, 1978.

Simmons, A. J. and Burridge, D. M.: An energy and angular momentum conserving vertical finite-difference scheme and hybrid vertical coordinates, Mon. Wea. Rev., 109, 758-766, 1981.

Slingo, J. M.: The development and verification of a cloud prediction scheme in the ECMWF model, Q. J. R. Meteorol. Soc., 113, 899-927, 1987.

Stajner, I., Riishojgaard, L. P., and Rood, R. B.: The GEOS ozone data assimilation system: Specification of error statistics, Q. J. R. Meteorol. Soc., 127, 1069-1094, 2001.

Stajner, I., Winslow, N., Rood, R. B., and Pawson, S.: Monitoring of observation errors in the assimilation of satellite ozone data, J. Geophys. Res., 109, D06309, doi:10.1029/2003JD004118, 2004.

Swinbank, R. and Ortland, D. A.,: Compilation of wind data for the Upper Atmosphere Research Satellite (UARS) Reference Atmosphere Project, J. Geophys. Res., 108 (D19), 4615, doi:10.1029/2002JD003135, 2003.

Teitelbaum, H., Moustaoui, M., and Fromm, M.: Exploring polar stratospheric cloud and ozone minihole formation: The primary importance of synoptic-scale flow perturbations, J. Geophys. Res., 106, 28 173-28 188, 2001.

Teixeira, J. and Hogan, T.: Boundary layer clouds in a global atmospheric model: Simple cloud cover parameterization, J. Climate, 15, 1261-1276, 2002.

Tiedtke, M.: The sensitivity of the time-scale flow to cumulus convection in the ECMWF model, Workshop on Large-Scale Numerical Models, 28 November-1 December 1983, European Centre for Medium-Range Weather Forecasts, 297-316, 1984.

Thomason, L. W. and Taha, G.: SAGE III aerosol extinction measurements: Initial results, Geophys. Res. Lett., 30 (12), 1631 , doi:10.1029/2003GL017317, 2003.

Trenberth, K. E. and Stepaniak, D. P.: A pathological problem with NCEP reanalyses in the stratosphere, J. Climate, 15, 690-695, 2002.

Urban, J., Lautié, N., Le Flochmoën, E., et al.: The northern hemisphere stratospheric vortex during the 2002-2003 winter: Subsidence, chlorine activation and ozone loss observed by the Odin Sub-Millimetre Radiometer, Geophys. Res. Lett., 31, L07103, doi:10.1029/2003GL019089, 2004.

Webster, S., Brown, A. R., Cameron, D. R., and Jones, C. P.: Improvements to the representation of orography in the Met Office Unified Model, Q. J. R. Meteorol. Soc., 129, 1989-2010, 2003.

World Meteorological Organization: Scientific Assessment of Ozone Depletion: 2002, Global Ozone Research and Monitoring Project-Report No. 47, 498, Geneva, 2003. 